Rozenblat C. (2021). Cities' systems and networks' proximities: toward a multiplex approach, in Torre A. Gallaud D. (eds.), Handbook on proximity, Chapter 9, Edward Elgar

\title{
Cities' systems and networks' proximities: toward a multiplex approach
}

Celine Rozenblat

Celine.rozenblat@unil.ch

Abstract: This chapter discusses the deep co-constructive relations between cities and proximities through networks, in a multi-dimensional and multi-level perspective. The proposed "multiplex" framework combines the multi-dimensional contribution of the Evolutionary Economic Geography with the multi-level theory of evolutionary cities' systems. This combination highlights the properties of the evolutive levels of organization (meso and macro) in multiple dimensions of networks, and describes how the induced proximities interact between these dimensions. The meso levels, where proximities are higher, create a high potential of networks' development and retention. In addition, the interactions between levels constitute an essential factor of dynamics. The diffusion processes occurring between levels and between dimensions define adaptive cycles which evolve in interaction all together. The multiplex proximity framework, shaping entangled cycles of dimensions and levels, is useful to better understanding and modeling cross-level and cross-dimensional policies in order to better support adaptation of cities' economies to global change.

Keywords: Cities, Urban systems, proximities, networks, relatedness, multi-level

Celine Rozenblat, Institute of Geography and sustainability, Faculty of Geoscience and environment, University of Lausanne, Switzerland

Céline Rozenblat is full professor of Urban Geography at the University of Lausanne (Director of the Institute of Geography and sustainability), vice-president of the International Geographical Union (IGU), member of the council of the Complex Systems society (Erdös $N^{\circ} 3$ ) and member of the International Science Council commission on Urban health. She works on the resilience of city networks in a multilevel urban systems perspective. 
Rozenblat C. (2021). Cities' systems and networks' proximities: toward a multiplex approach, in Torre A. Gallaud D. (eds.), Handbook on proximity, Chapter 9, Edward Elgar

Spatial proximity is one of the first property of cities, grouping neighbor people and close activities in a structured spatial and socio-economic organization of exchanges, where numerous and strong interactions mostly develop within about one hour of travel (Bretagnolle \& Pumain, 2010). Thus, it implies immediately that the proximity in cities does not only concern geographical space, but also social, economic, institutional interactions creating temporal or long-standing intertwined networks. These networks support and enhance (or not) many other proximities between people than the single spatial proximity. These proximities are grounded on family linkages, associations, friendships, coworking, inducing imitations, learnings between individuals. Between enterprises and institutions diffusions also occur through collaborations, subcontracting, share of services, training, co-inventions and so on... In these multiple dimensions of the social life, respectively created by partly independent networks, the question of spatial proximity facing other kinds of social, institutional or economic proximities, is thus particularly prominent for cities.

The natures and intensities of the combinations between geographical, cognitive, organizational, social and institutional proximities are at the core of the reflections on the dynamics of production and diffusion of knowledge within innovation networks developed by the Evolutionary Economic Geography (Torre \& Rallet, 2005; Boschma, 2005; Boschma \& Martin, 2010; Boschma \& Frenken, 2010; Massard \& Mehier, 2010; Autant-Bernard et al., 2014; Torre \& Wallet, 2014; Rallet \& Torre, 2017). Considering innovative networks in their multiple networks (Cassi \& Plunket, 2014), i.e., features of their constituents, different dimensions of proximities are more and more combined all together. We can wonder more specifically in which extent the spatial proximity offered by cities sustain emerging innovation networks and their diffusion, and at the opposite, how far the multiple proximities participate to the building, the maintain and the evolution of cities.

Cities as places only exist through the social and economic networks that create them: "Places and networks should no longer be considered as separate interactive processes, but rather as forms of spatial organization that are intrinsically co-produced"...(and)... "the city is not only viewed as an aggregation of multiple networks, but also as an interconnection node between networks" (Pflieger \& Rozenblat, 2010: 2725). This chapter proposes to stress the conceptual and methodological issues arising when one assumes the mutual formation between the proximities provided by cities considered weather as "spaces of places" (spatial proximity) weather as "spaces of flows" (Castells, 1996) (comprising social, economic, institutional networks that create other proximities not only dependent to space).

But cities, beyond supporting spatial proximities at the local scale, also leverage proximities at the global scale permitting to reach far cities or places, by offering long distance infrastructures and socioeconomic channels. In this sense, cities support the densification and the complexification of social and economic networks both locally and globally. Thus, intra-cities' proximities and global accessibilities combine in the formation and continuation of all the kinds of networks' dynamics providing local and global conditions that constitute multi-level urban systems (Pumain, 2006). Evolutionary complex urban systems approach addresses at these two levels how far emergence and diffusion of innovation boost cities' transformation ${ }^{1}$ (Pumain, 2006; Batty, 2007; Bettencourt et al., 2007; Bretagnolle et al., 2009; Pumain et al., 2009). Urban systems (macro-level) are adaptive complex systems where distributed growth and interaction between cities afford emergent properties affecting in feed-back loop the development of every single city (meso-level). Despite the continuous diffusion of innovation waves from cities to other ones, cities unevenly adapt their structures to new innovations waves, some cities losing their leadership in some sectors, other taking advantage in the emergence of new innovative industries (Pumain et al., 2009). But it is less clear why their trajectories underline a main trend of co-

\footnotetext{
${ }^{1}$ innovation is taken here in a very wide meaning as "New products, or new technology, as well as new social practices, which in general are more long-lasting than mere fashions" (Pumain et al., 2009)
} 
Rozenblat C. (2021). Cities' systems and networks' proximities: toward a multiplex approach, in Torre A. Gallaud D. (eds.), Handbook on proximity, Chapter 9, Edward Elgar

evolution in socio-economic space, and why cities' systems remain so stable in the multi-dimensional evolving networks?

Similar to spatial proximities, the other proximities, also admit different levels of organization because the networks that constitute them are not random but rather structured by "small worlds" (Watts \& Strogatz, 1998; Fleming et al. 2007; Breschi \& Lissoni, 2004) that create different groups or "clusters" corresponding or not to the geographical proximity provided by cities. A multi-level approach is thus necessary to integrate in each dimension. However, as far as we know, the multiple proximities constitutive of innovative networks - superbly and rigorously developed by the evolutionary economic geography - has never been integrated in multi-level approach.

Both approaches of Evolutionary Economic Geography and of Evolutionary Complex Urban Systems seem very complementary, highlighting multi-dimensions for the former one, and multi-level for the latter. Thus, as they are based on quite similar concepts of path dependence and complex adaptive systems, we propose to combine them in a unique framework. In this chapter, we argue that the combination of these multiple proximities, each considered within a multi-level system perspective, would better provide comprehensive ground for the design and evaluation of entangled sectoral and spatial public policies. The goal is thus to question these multiple dimensions and levels of networks' proximities, in their capacities to renew the collective capacity of cities' actors by spatial proximity.

We propose a methodological framework based on the "multiplex" approach of networks, now very popular in Complex System Science (Battiston et al., 2018), applied on the combination of urban systems and innovative networks concepts. The multi-dimensional approach of these networks, where multiplex spatial networks (1) defining multiple natures of proximities (2), will be combined with their multi-level systems (3) in order to build a classification of policies highlighting the potential systemic role of proximities through networks (4). In this stepwise progress, the third and fourth parts will question the regulation processes and the degree of freedom existing in such socio-economic systems.

\section{1- Multiplex innovation networks}

The behavior of individuals, the organization of private or public institutions and the dynamics of geographic spaces are based on networks of uneven natures driven by actors who often belong, each of them, to several networks. Networks of actors appear and disappear, interacting with each other by some reinforcement or competition interactions. These inter-relations can take the form of information exchange, co-operation, competition or exclusion, depending on the strategic investment of actors in the social and institutional networks and on which extend the powers and the rules are organized and distributed within a single network or between multiple networks (Castells, 2009).

In addition, the social construction of innovation networks is based on a multitude of more or less dependent projects - which may appear simultaneously or successively - rather than on initiatives that strictly belong to a group sharing the goals of a single unified project over the long-term. While historically it has been usual to distinguish between formal and emerging networks (Aldrich, 1976), an interesting alternative consists in studying both together, allowing the accumulation of the actions of emerging networks to broaden the boundaries of formal ones (Monge \& Contractor, 2003).

Thus, each innovation depends on the whole context of intertwined, overlapped, sometimes nested networks into economic, social, organizational or spatial communities that evolve in time. Networks 
Rozenblat C. (2021). Cities' systems and networks' proximities: toward a multiplex approach, in Torre A. Gallaud D. (eds.), Handbook on proximity, Chapter 9, Edward Elgar

elaborated between different kinds of actors, institutions, technologies, ideas or artefact, and defined by different kinds of linkages, form "Multiplex networks"2 (Fig.1).

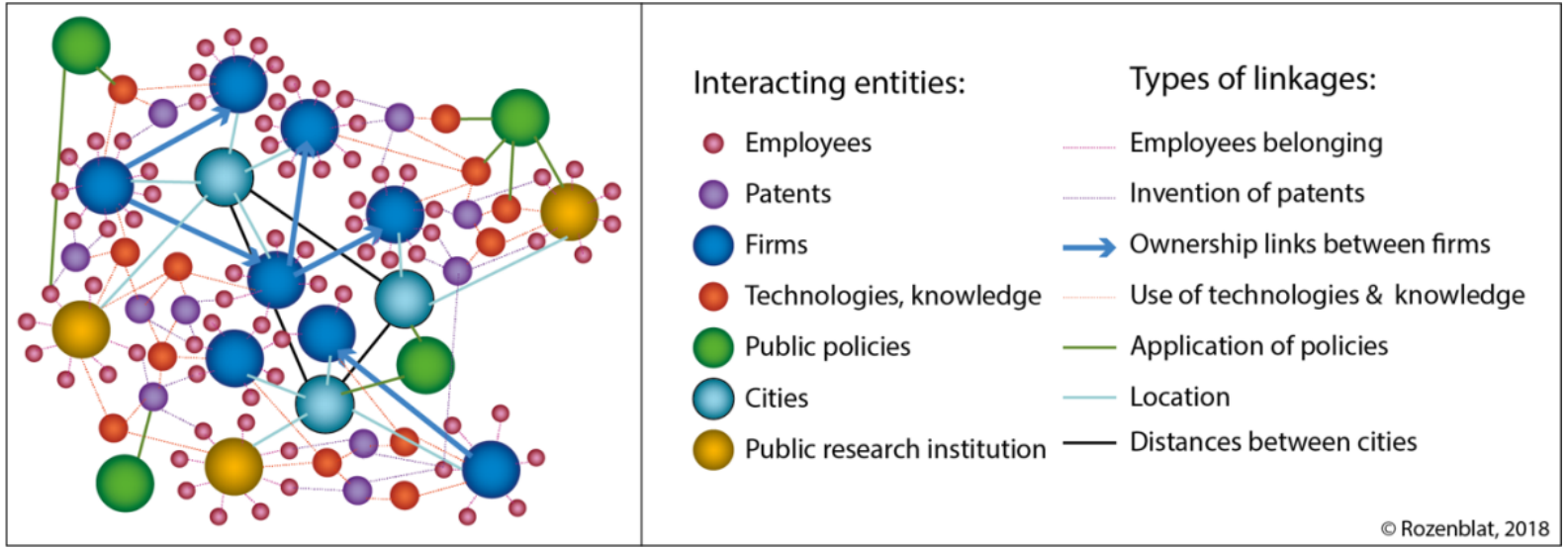

Figure 1: Example of a multiplex innovation network

In the example of the figure 1, employees belong to one or to several firms or to public research institutions. Some employees create patents sometimes in collaboration with other employees belonging either to their own firm either to other firms or institutions. Employees develop their own networks, for example coming from their school years or from their move from a firm to another one or from their participation to clubs, family networks or more or less formal meetings. Despite there are no direct links in the scheme of Figure 1 between employees, because we focus on their participation to "actions" or "objective facts", their common belonging to firms or institutions or their co-invention of patents with others, induce "equivalence" 3 permitting to suppose direct links between them that define their proximity". This assumption refers obviously to the difficult articulation between organization and individuals, particularly concerning coordination proximities and institutional proximities (Bouba-Olga \& Grossetti, 2008; Lazega et al., 2008). We will not enter here in this debate, simply assuming that by all these actions and facts, numerous experiences contribute to explore, build, maintain or remove relations between employees inside or outside firms or institutions (Monge \& Contractor, 2003). In addition, the spatial or territorial proximity also favors potential of interactions. This is illustrated on Figure 1 by the location in the same cities. Besides, cities are physically distant to each other, referring to all the kinds of gravitation models (Tobler, 1975). By this way, two cities are closer if their physical distance is low, or because they belong to the same country or region, or because they share many social or economic networks.

\subsection{Structural proximity properties}

By the equivalence properties which constitute network proximities, firms, groups of firms or public institutions are particularly critical contexts contributing to boost individual creativity and to stimulate collaboration. Internal management of enterprises and conditions of competition within each specific domain can favor or at the opposite restrict innovation and collaboration. The fields of technologies and knowledge matter a lot, creating some specialization of firms or of employees, and enabling to bring

\footnotetext{
2 There is not a unique admitted definition of what "Multiplex networks" are. "Historically, the term multiplex has been adopted to indicate the presence of more than one relationship between the same actors of a social network" (Padgett \& Ansell, 1993 ; Gomez et al., 2018). Today this kind of network is rather called multimodal or multilayer (and with different kinds of nodes it is called multipartite). A multiplex network can rather be defined as simultaneously multimodal and multipartite. According to the construction, these networks can take the form of interconnected networks, or "networks of networks" (Contractor, 2009)

${ }^{3}$ The notion of "equivalence" was first introduced by Lorrain \& White (1971) in sociology, and was extended in the social network terminology with 3 distinctive definitions (Borgatti \& Everett, 1992; Wasserman \& Faust, 1994):

Structural equivalence: 2 nodes are structurally equivalent if they have identical ties to and from all other nodes in the network; Automorphic equivalence: 2 nodes are automorphic equivalent if they occupy indistinguishable structural locations in the network; Regular equivalence: 2 nodes are regularly equivalent if they occupy the same position related in the same ways with other nod es which are themselves in the same position

Regarding the extend of these definitions, structural equivalence is more restrictive than automorphic equivalence, which is itself more restrictive than regular equivalence.

${ }^{4}$ see the extensions of this example in Figure 4 and Figure 5 below
} 
Rozenblat C. (2021). Cities' systems and networks' proximities: toward a multiplex approach, in Torre A. Gallaud D. (eds.), Handbook on proximity, Chapter 9, Edward Elgar

closer complementary fields or knowledge (more concretely the employees or firms developing them). But it is not so clear how complementary knowledge come closer? Some technologies are more central ${ }^{5}$ than others in these networks of proximities at certain moments of time, because they are incorporated in many various products. New technologies emerge and are likely to produce burst of innovation cascades through "network experiences" comprising both "path dependence" (Liebowitz \& Margolis, 1995) and "cycles of learning" (Padgett \& Powell, 2012), all being boosted by the co-evolution of social networks of individuals, firms and institutions: a high issue for the possible emergence of a new fruitful convergence between two technologies is to appear together at the right place and the right moment.

In this respect, cities have specific properties like local density and diversity of people, communities and amenities, regional and global accessibility and attractiveness that strengthen the likelihood for such network exchanges. Spatial proximity enhances knowledge and information spillovers through lower communication costs and a greater likelihood of positive meetings (serendipity) (Storper \& Venable, 2004). Digital communication increases social relationships especially between suppliers, buyers, lead users, researchers, etc. The importance of positive local knowledge externalities for innovation in cities has already been widely observed and measured in various empirical studies (Jaffe, 1989; Jaffe et al., 1993; Audretsch \& Feldman, 1996; Breschi \& Lissoni, 2005).

However, most studies focus only on geographical space or on technologies and are either based on individual networks either on spatial entities like regions or countries. The improvement in the understanding of the multiple interdependencies between different structural dimensions (different networks) and levels (micro, meso and macro), critically needs an integrated approach combining these multiple dimensions and putting together the partial evidences in the multi-level system. Global networks diffusing knowledge and innovation are produced by numerous kinds of markets, organizations and social linkages that are reduced in most studies because of the lack of data at this global scale (Taylor, 2014). In particular, because of the urban data unavailability, most of the studies are undertaken at the regional level, while processes that are mostly urban, are often hidden by regions' perimeters that do not correspond to the social and economic systems: some regions encompass different cities while some cities spread over several regions. Functional large urban areas delineations are more adapted in order to better catch the urban processes of dense local interactions (Cattan et al., 1999; Bretagnolle et al., 2009; Lennert et al., 2011; Rozenblat, 2019). However, this urban approach is more difficult to pursue because of the multiple aspect of these urban functions. The question of the interaction of cities and proximity with innovation emergence and diffusion, cannot avoid a clarification of the considered objects and subjects. Clarifying these basic elements necessitates to start from the individual perspective of actors, in order to rebuild the whole social processes at work, involving cities, their actors and their relations.

\subsection{Network approach, actor-network and assemblage theory}

The perspective that actors and their relations are mutually constitutive, is similar to the one of the "actor-network" theory, that expresses a complex network from all of its "actants". Actants can be people as well as institutions, texts, material or technical artifacts, all operating in the networking processes (Callon, 1986; Law \& Hassard, 1999; Akrich et al., 2006). Thanks to this topological perspective, interesting features have been analyzed like the formation of communities of practice (Amin \& Cohendet, 2004), or like "translations" processes permitting the progressive constitution of

\footnotetext{
${ }^{5}$ Centrality refers to the centrality in the built network. Three main families of centralities are usually measured: Local centralities: how many links each node have, which is called "degree";

Global centralities: in which extend a node is accessible by all the other nodes of the network. Here numerous measures evaluate differently this centrality like Reachability (what is the topologic distance between a node and all the other nodes) or Betweenness centrality (how many shorter paths from all couples of nodes pass by the node);

In between local and global centralities: Eigen vector centrality measures how much the neighbors of a node have a high degree, with an acceptation of neighborhood that can vary from 1 (immediate topologic neighbors) to the diameter of the total network (longer distance between nodes) (Bonacich, 2007).

All these measures can be weighted or not and / or oriented or not.
} 
Rozenblat C. (2021). Cities' systems and networks' proximities: toward a multiplex approach, in Torre A. Gallaud D. (eds.), Handbook on proximity, Chapter 9, Edward Elgar

communities of interests (Callon, 1986; Müller, 2015). In addition, the topological approach permits overpassing the dualisms local/global. The "assemblage theory" that succeeded to the "actor-network theory" goes further in the aim at defining spatiality and temporality of the capacity of spread elements able at one moment and in one place to assemble and temporary compose a socio-spatial formation (Marcus \& Sacca, 2006; Phillips, 2006; Mc Farlane, 2009; Anderson \& MacFarlane, 2011).

Despite considering the "agencement" of performative practices in certain configurations (Braun, 2016), these approaches do not address the structural properties in themselves, but rather the behavior of agents in such structures taken as support of action. But actor-network theory does not search any structural regularity. Thus, the "actor-network" theory and the "assemblage theory" have conceptual high interest, but they do not bring the coherent framework one needs to identify network's structural and dynamic properties in their numerous dimensions.

\subsection{Multiplex approach}

The structural investigation of the networks' multiple dimensions can be rather addressed through the multiplex approach developed in Complex system science, which elaborated for 20 years, theories and methods modeling dynamics in such complex topological structures (Gomez et al., 2018). It would be too much restraining to limit multiplex approach to simple sets of tools. The multiplex approach, through its formalizations, decomposes precisely each network according both to the nature and strength of its elements (Kivelä et al., 2014) in order to address theoretical questions about the systemic emerging properties and their supporting structures.

In this perspective, one considers any kind of object or property as actor, activity, innovation, communication infrastructure or software, policy, institution, acknowledging their role in the constitution of the territorial complex system. Methodologically, by categorizing the kind of objects and relations, one makes some choices: categories can be either attributes, either linkages or groups of nodes (clusters). In any cases, a first stage is necessary to define if the network is "multi-partite" because it gathers different kinds of actors, and if it is "multi-modal" because linkages mean different kinds of relations. This stage constitutes a critical qualitative step: by this way, a large qualitative part roots the quantitative approaches and this is why the qualitative approach cannot be opposed to the quantitative one.

\subsection{The nature of actors and interactions: The questions addressed by multi-partite networks}

Handling different kinds of actors necessitate that actors, objects and concepts would rigorously be defined and delineated in a strong ontology. The heterogeneous social networks of strategic alliances, joint ventures, university-firm collaborations, and institutional actors form together some modular "innovation systems" (Nelson, 1993) based on "innovation networks". In fact, agents are individuals but may also be institutions, or even objects, knowledge or opinions (Musso, 2003; Monge \& Contractor, 2003; Latour, 2005). In this respect, Contractor et al. (2011) proposed that because "new technologies can simultaneously shape and be shaped by the social networks into which they are introduced (...) it makes more sense to begin to treat technologies as endogenous to network relations rather than exogenous to them. In other words, instead of asking how technologies might change networks (or vice versa, or both), perhaps the more appropriate question for our times is: "What happens when a new technology becomes a part of a social network?"'" (Contractor et al., 2011: 684).

There is no problem to deal with different kinds of interacting objects, as soon as agents (that in networks represent nodes also called vertices) are categorized precisely to define what is called "multitype networks", "heterogeneous networks" or "heterogeneous information networks" (Cai et al., 2005). This is what we did in figure 1 by distinguishing the different natures of nodes: employees, firms, research institutions, patents, technologies-knowledge, policies and cities. Cities here represent a 
Rozenblat C. (2021). Cities' systems and networks' proximities: toward a multiplex approach, in Torre A. Gallaud D. (eds.), Handbook on proximity, Chapter 9, Edward Elgar

location, a territorial belonging or a governance that permit to link (and create proximity) between actors or technologies by their equivalent location.

Step forward, a critical issue is to discuss the level of nomenclatures' precision in order to define the "granulometry" of sectors that must be uncovered, for example, in the "smart specialization" policies (Foray, 2014). This step is complicated by the fact that the various kinds of agents are described by nomenclatures of technics or knowledge, based on rather different logics. For example, firms are usually described by their activity sectors (NACE: Statistical Classification of Economic Activities [European Community classification] or SIC: Standard Industrial classification [US classification]), but patents are qualified by their technologic components (IPC: International Patents classification), and for products, it is another nomenclature elaborated by the World Trade Organization, called Standard International Trade Classification (SITC). Fortunately, some international statistical institutions produced correspondences between these nomenclatures, as it is the case between IPC and NACE (Van Looy et al., 2014). As a consequence, in the network represented on figure 1, firms, research institutions and patents are relied to the same "technology and knowledge" nodes, thanks to these concordances between IPC and NACE.

\subsection{Multi-modal or multi-layer networks}

Networks are finally defined by the existence of linkages between nodes, revealing neighborhoods that define proximity. The neighborhoods can be defined as one step linkage (direct), but also by two steps or more (indirect or equivalent). The linkages between nodes are more critical to define qualitatively. According to the different meanings of relations and their capacity to define proximity, one can fragment the whole network in different networks in order to build a multi-layer network (Fig.2).

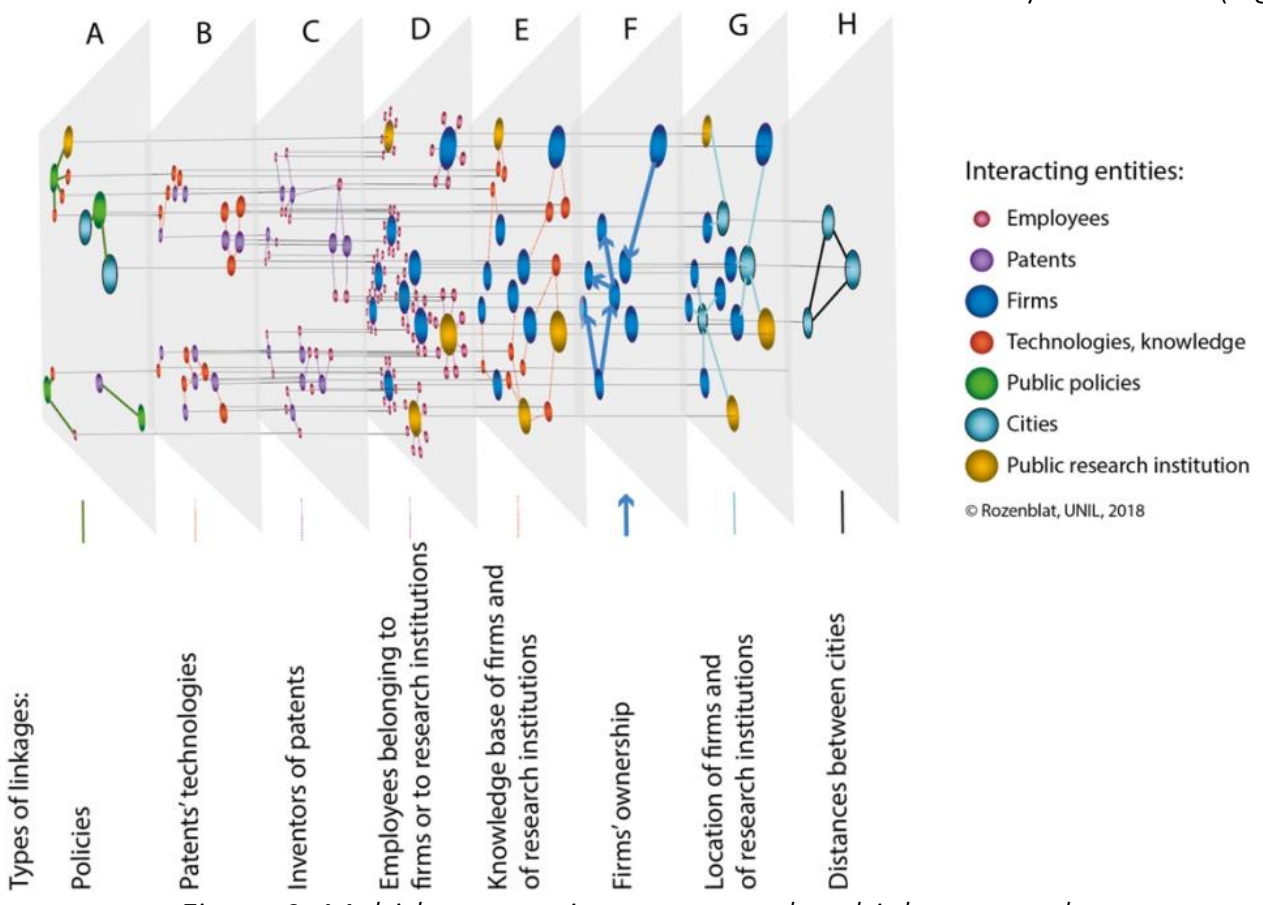

Figure 2: Multi-layer non-interconnected multiplex network

In figure 2, we represented exactly the same information than on figure 1, but in a more disaggregated way by putting each kind of linkage in one distinct layer: Thus, every layer becomes unimodal with only one single kind of links for each. The whole multi-layer network is non-interconnected multiplex because the links between layers are only underlying the same nodes appearing simultaneously on different layers. These nodes play the role of intermediate, allowing to other kinds of nodes to have indirect proximities. 
Rozenblat C. (2021). Cities' systems and networks' proximities: toward a multiplex approach, in Torre A. Gallaud D. (eds.), Handbook on proximity, Chapter 9, Edward Elgar

Otherwise, interconnected multiplex networks express a supplementary cost (or weight) on the interlayer to link different nodes of the different networks. For example, we could transform a part of the network of the figure 2 into a multi-layer interconnected multiplex network if the D layer becomes interlayer linkages between the layers $\mathrm{C}$ and $\mathrm{E}$ (Fig.3).

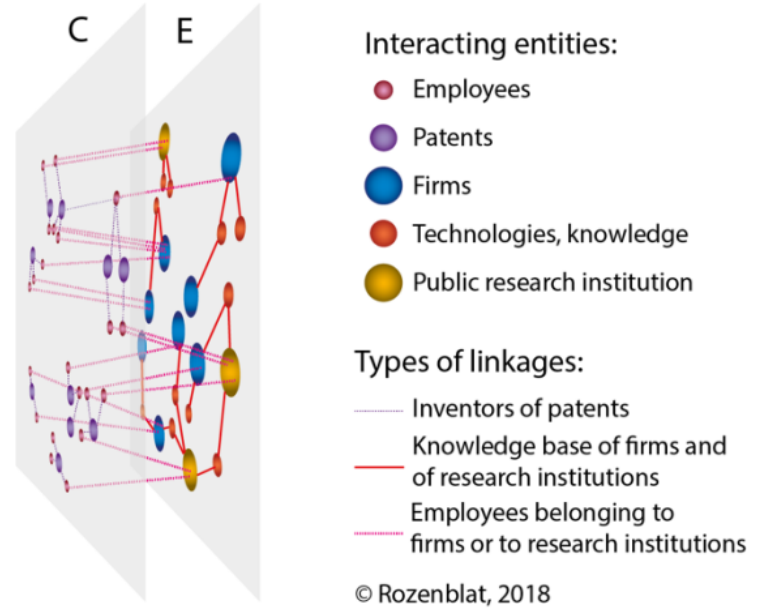

Figure 3: Multi-layer interconnected multiplex network

This reduction of layers, beyond performing better compact calculation (Gomez et al., 2018), permits to underline some specific interaction composing the proximity. Here for example, the inter-layer network underlines the fact that employees and their patents are closed to certain knowledge only because they belong to certain firms that develop common knowledge.

\section{Multiple proximities of innovation systems}

Such multiplex approaches are very consistent with innovative networks as composed by multiple actors and multiple relations inside or between cities. Innovative networks at once adapt to existing urban contexts and transform them (Giddens, 1984). In this way, Dicken et al. (2001), suggest that social networks should be considered as being both structural and relational: structural inasmuch as they are constituted of established networks - such as infrastructure networks or networks of forces - and relational because they also link agents in a wide variety of domains. Consequently, in each domain, one can evaluate proximity between actors, and combination of proximities are facilitated by the multilayer approach.

\subsection{Building multiple proximities inside the same system}

The spatial and organizational proximities and the density of social links act as substitute of coordination mechanisms that combine with the technological proximity (or knowledge), distance in institutions, social and organizational proximities (Torre \& Rallet, 2005; Kirman \& Zimmermann, 2012; Bouba-Olga \& Grossetti, 2008). Thus, the proximities are multiple, not always dependent to each other creating a network in multiple dimensions. The multi-layer networks can help to distinguish the different dimensions and to test their relations and combinations. It allows to better understand the selforganized systems, that are far being organized or managed intentionally by one unique coordination organism (Roth \& Cointet, 2010; Cassi \& Plunket, 2014). For example, an equivalence in the multi-layer networks can help to evaluate proximities among inventors according to their past mutual cooperation, that firms can use to better coordinate their cooperation (Fig.4-1). 
Rozenblat C. (2021). Cities' systems and networks' proximities: toward a multiplex approach, in Torre A. Gallaud D. (eds.), Handbook on proximity, Chapter 9, Edward Elgar

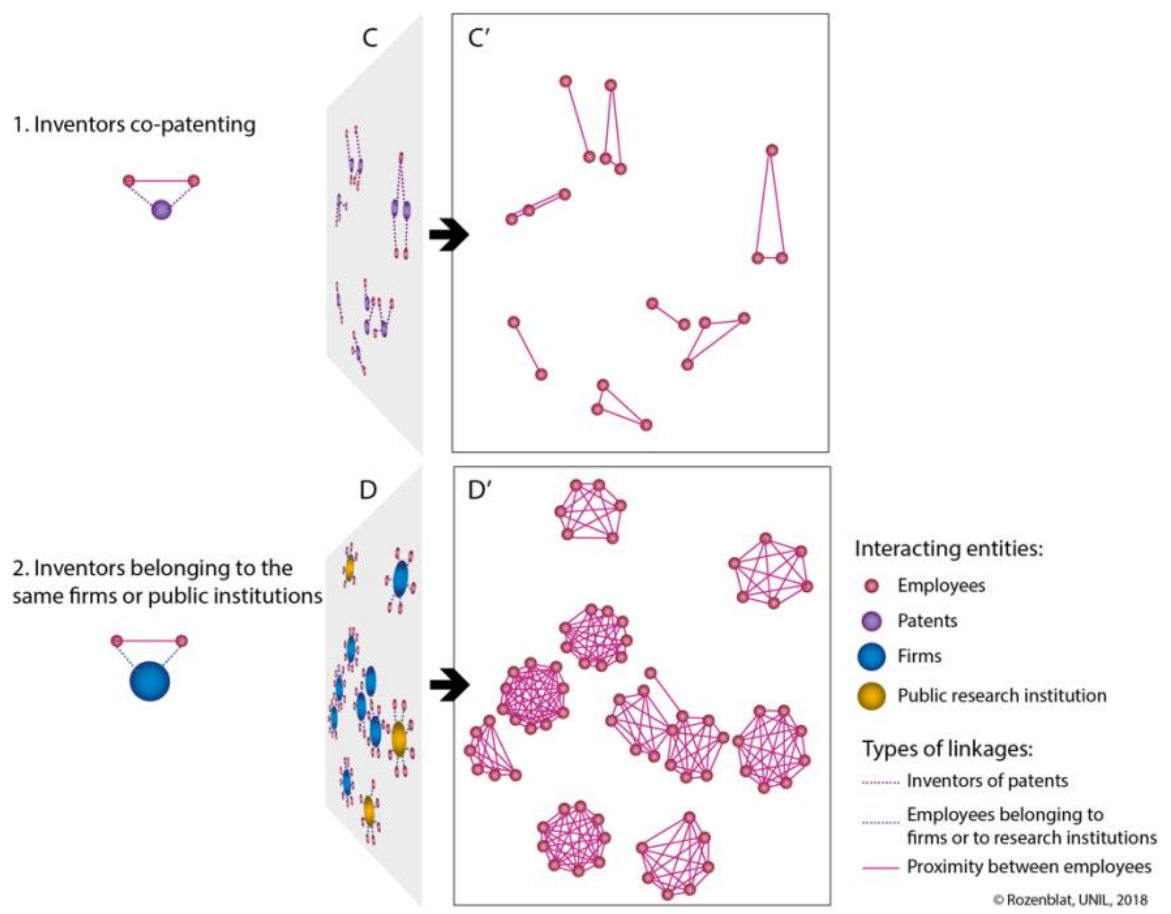

Figure 4: Building proximities between inventors

Two inventors can have different degree and experience of mutual collaboration, so the distance is gradual rather than binary like it is the case of "structural equivalence". More inventors collaborate to the same patents, more they are closed and if they belong also to the same firm, their proximity is even higher, because two kinds of network link them, one of cooperation and the other organizational, like it is drawn in the other figure based on the belonging to the same firms (Fig.4-2). This information and its easy accessibility can help firms or decision makers to identify and target people able to involve others, in the integration a new value or idea, by using the strong link between people, and thus increasing the likelihood of propagations for information passing through them.

Sociologists and communication scientists produced numerous evidences on the structural capacity of social networks to facilitate meetings, sharing, building of common projects and possibly leading to new innovations. Individual behaviors like exploring, exploiting, mobilizing, bonding or swarming the networks refer to numerous theories framing social networks analyses: theories of self-interest, theories of mutual interest and collective action, cognitive theories, cognitive consistency theories, contagion theories, exchange and dependency theories, homophily theories, proximity theories, and theories of network evolution and coevolution (Poole \& Contractor, 2012). All these theories highlight several properties of behaviors that were observed on different groups of people in uneven situations. Inventors have more likelihood to collaborate if they have common interests (mutual interest or collective action), if their proximity in terms of technology or activity is high (cognitive distance), or if they have similar training (homophily), or if one of them is a mentor who is attractive to others for his advice capacity (self-interest) ...

\subsection{Technology or activity spaces revealing the system of proximities}

Exploring technology diversification and knowledge combination opportunities, can also help to support technology forecasting and road mapping practices. Jaffe (1986) was the first one to build such "technologic spaces" using the correlation between firms' patents in a sets of technology fields. The approach consists in considering the equivalence of technologies regarding the distribution of their networks among a second kind of nodes (Fig.5-1) or even with an indirect series of nodes (Fig.5-2 and Fig.5-3): 
Rozenblat C. (2021). Cities' systems and networks' proximities: toward a multiplex approach, in Torre A. Gallaud D. (eds.), Handbook on proximity, Chapter 9, Edward Elgar

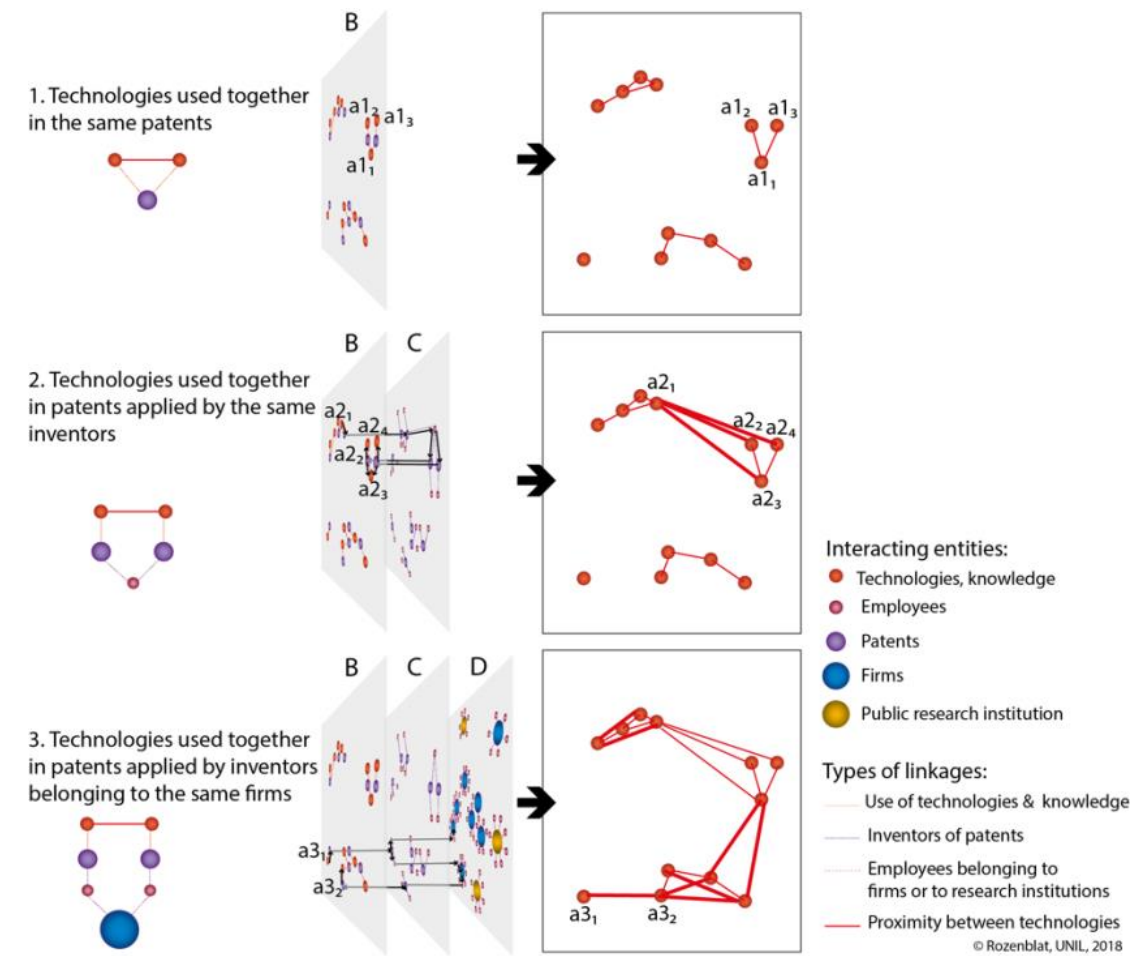

Figure 5: Several examples to evaluate proximities (relatedness) between technologies

In this perspective, proximities are no more applied between actors or firms, but rather between what qualify them: their activities or their technologies. In Figure 5, technologies qualify patents that are produced by inventors who are employees of firms. Proximities between technologies can be defined either according to the number of patents using simultaneously these technologies (Fig.5-1), either because technologies qualifying patents were applied by the same inventors (Fig.5-2), or because technologies qualify patents that were applied by inventors belonging to the same firms (Fig.5-3). Several levels of equivalence are used in these three examples, depending on the number of steps considered in the equivalence measure. These are few examples among numerous ones that can define proximities between technologies.

The calculation of proximities between technologies is generally based on the cosine index (COS) measuring the angle between two vectors. Each vector characterizes the distribution of a technology among patents (in Fig.5-1) or inventors (in Fig.5-2):

$$
\cos (i, j)=\frac{\sum_{f \in F} \operatorname{Ind}_{i}(f) \operatorname{Ind}_{j}(f)}{\sqrt{\left(\sum_{f \in F} \operatorname{Ind}_{i}(f)\right)\left(\sum_{f \in F} \operatorname{Ind}_{j}(f)\right)}}
$$

$i$ and $j:$ two different technologies

$f$ : an inventor in a set of $\mathrm{F}$ inventors

Ind $d_{k}$ : indicator function, which for any technology $k$ is equal to 1 if $f$ practices $k$ and 0 otherwise

Numerous authors implemented this calculation of proximities between technologies, activities or products in order to build "product spaces" at international scale using international trade (Hidalgo et al., 2007), "technologies' spaces" at national or regional scales (Frenken et al., 2007; Content et al., 2016), assuming that the general capacity of firms to develop further, is linked to the presence of firms with related activities able to support their own activities (Hidalgo et al., 2007);

Yan and Luo (2017) built technology spaces for all USA patents applied from 1976 to 2006, comparing twelve measures of distances with different variant of technologies' co-references (technologies of patents citing same source patents), inventor diversification likelihoods (technologies of patents produced by the same inventors), and co-qualification of patents (co-occurrence). Yan and Luo (2017) 
Rozenblat C. (2021). Cities' systems and networks' proximities: toward a multiplex approach, in Torre A. Gallaud D. (eds.), Handbook on proximity, Chapter 9, Edward Elgar

conclude that normalized coreference and inventor diversification likelihood measures are the best representative measures regarding their ability to summarize all the other dimensions of proximity. As we could expect, technologies' proximities depend mainly on their inventors' capacities to combine them (inventor diversification likelihood) and on their bounded knowledge referencing to other patents. Their own technology and social knowledge build the technologies' future potential of extension or combination. Thus, actors' capabilities and limits remain central in the proximities between technologies as far as they create, develop and use them.

One can conceptualize numerous proximities, either between technologies, between activities, between occupations (Farinah et al., 2019), that must be distinguished from the different proximities evaluated directly between actors (Balland et al., 2015). Proximities between technologies or activities are generally evaluated at an average national or worldwide level and then are used to better qualify the relatedness of the firms located in specific regions or cities. The method proceeds in two steps:

- First, at the scale of countries or of the world, one evaluates proximity of activities thanks to their exchanges (in input-output matrixes) or similarities in occupations and jobs, or in technology;

- Second, these average proximities support the calculation of the relatedness between specialized activities of cities or regions inside a considered space. This calculation can be made by different ways, also depending of the nature of the data (For example, the conditional probability used by Hidalgo et al. [2007] is not always possible ${ }^{6}$.

During the first step, an "activity space" represents a matrix of proximities between activities. For the following example, we built the space of activities according to their co-practice by firms (firms developing several activities, here with the NACE 2 Digits nomenclature). The representation of the "activity space" emphasizes the related sectors supporting the economy of the whole system of cities, as we can illustrate with the example of the main multinational and national firms in China (Fig.6).

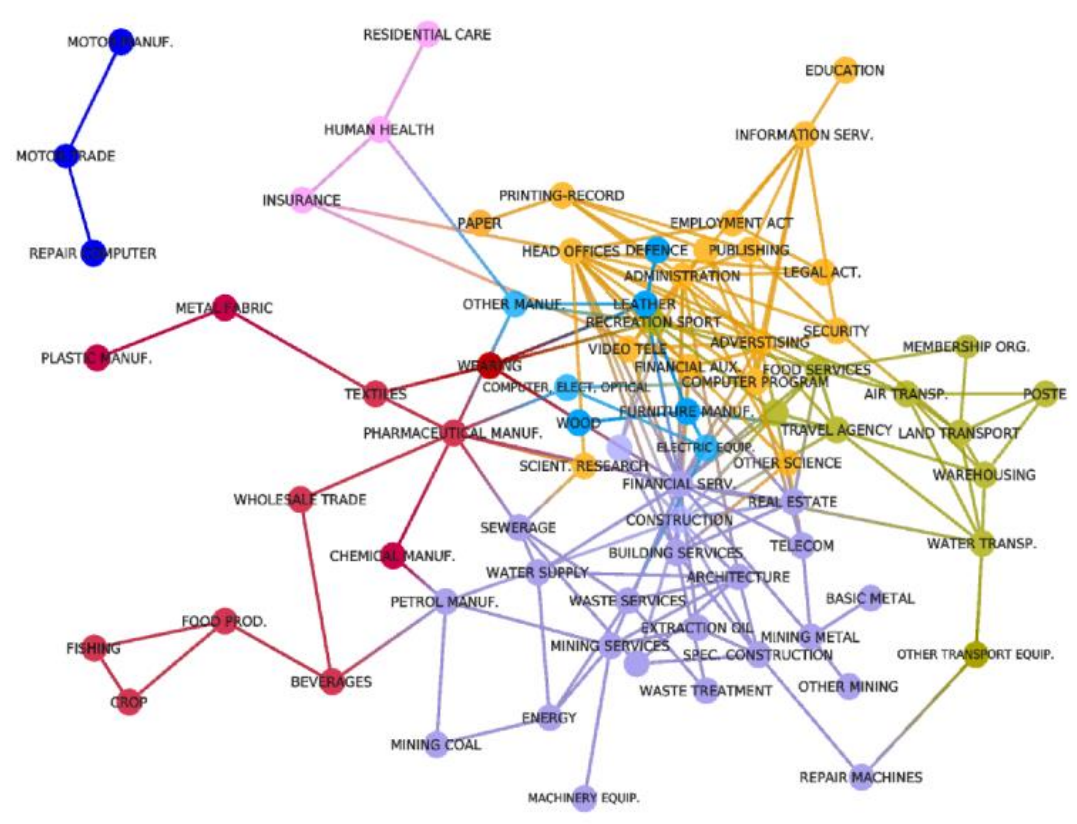

Closest activities

(Louvain clustering)

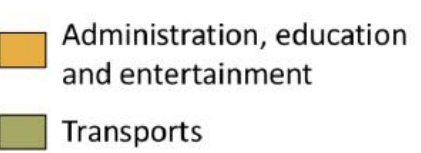

Manufacturing

Energy, construction, Financial services

Health \& Insurance

Motor industry

Food, textile, pharmaceutical

Proximity between

activities: $\cos >0.001$

CSwerts, Rozenblat, Bida, 2018

Source of data:

ORBIS, BvD, 2016 \& UNIL, 2018

Figure 6: Activity space of multinational firms in China in 2016

The activity space informs on the closest or most related activities. Here in China, industry occupies a most central place because of the last 30 years dedicated by the Chinese economy to occupy the

\footnotetext{
${ }^{6}$ For example, Shutters et al. [2015], using occupation of people of US Metropolitan Statistical Areas (MSA), defined the relatedness as a "tightness" for each MSA with the sum of the product of the relative importance of employees of all couples of occupations weighted by these occupations' frequency of co-specializing the same cities (high Quotient locations)
} 
Rozenblat C. (2021). Cities' systems and networks' proximities: toward a multiplex approach, in Torre A. Gallaud D. (eds.), Handbook on proximity, Chapter 9, Edward Elgar

function of workshop of the world. Nevertheless, Chinese industry evolved very rapidly for 15 years, and all cities grew, trying to produce and attract more technological skills through universities and engineering schools. This figure represents a national average which can constitute a reference for comparisons to more restrained spaces like cities following the method of Hidalgo et al. (2007).

\subsection{Cities' relatedness and diversity}

The profile of cities within the average activity or technology spaces is an important issue to understand how far activities' proximities could form and transform them. Each city develops a port-folio of activities and the question is to which extend these activities are close or not, and to which extend these proximities bring some potentials of activities' mutual development and what is the scope of possibilities for future expansion and transformation. Different indices (Frenken et al., 2007; Shutters et al., 2015) synthesize this relatedness of activities appearing in each city, according to the proximities between activities calculated for the whole urban system.

The question of diversity versus variety properties for cities and regions has been treated in the literature for more than 20 years. It specifically focused on MAR (specialization) versus Jacobs (diversification) processes (see for a complete review De Groot et al. [2015]). Frenken et al. (2007) suggested that Jacobs' processes create "related variety" and must be distinguished from a wider diversification of activities. They proposed three basic theoretical hypotheses associated respectively with specialization, related variety and un-related variety (diversity):

1- MAR specialization (localization economy), "stemming from the spatial concentration of firms in the exact same industry (...) would enhance process of innovation as specialized knowledge is used to optimize production processes in existing value chain" (Frenken et al., 2007: 2098). Thus, they assume that specialization supports the growth of productivity;

2- Jacobs' related variety supports innovation and regional development in another way, creating more jobs because central activities multiply other ones; thanks to this multiplication, they assume that it fosters jobs' growth, and we can suppose that it could specifically concern younger activities regarding the lifecycle theory; 3- $\quad$ Unrelated variety (economies of urbanization) meaning a high variety of non-related activities, does not multiply jobs neither improve productivity, but it reduces unemployment growth in time of crisis for some sectors.

Frenken et al. (2007) validated these three hypotheses by measuring indexes of industrial composition for each property in Netherlands' regions. Besides, Cassi \& Plunket (2014) demonstrated that technological proximity (or knowledge) leverages particularly innovative performance, within or between regions, so exceeding spatial proximities that add a significant potential. Thus, technological proximities inside cities are the best combination to foster innovation. If we keep the example of the Chinese space of activities (Fig.6), medium size cities like Datong or Zhuhai, living strong transformations with the insertion of China in the globalization, recently experimented policies encouraging the related diversification of their economy and thus supporting the location of new related activities, close to their core historical industries (Fig.7). 
Rozenblat C. (2021). Cities' systems and networks' proximities: toward a multiplex approach, in Torre A. Gallaud D. (eds.), Handbook on proximity, Chapter 9, Edward Elgar

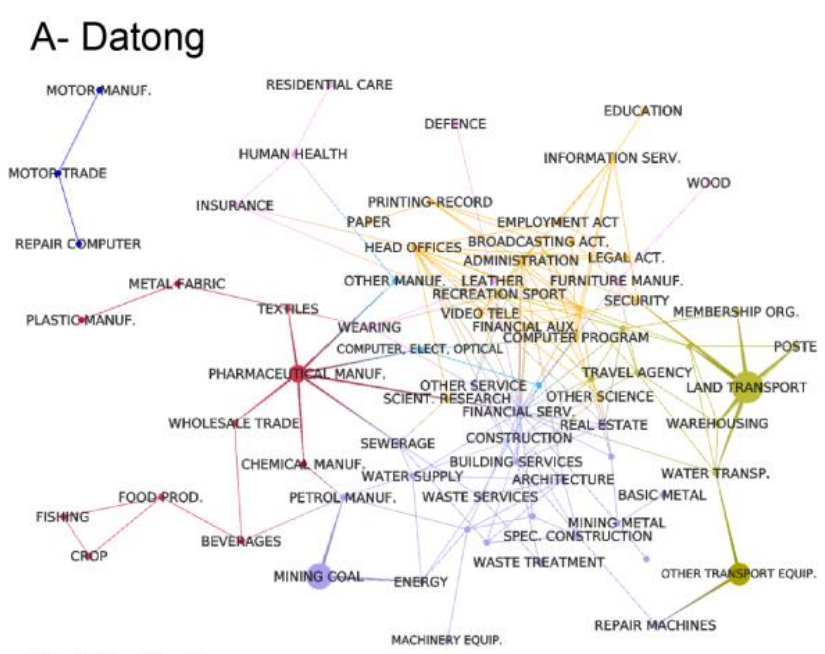

B- Zhuhai

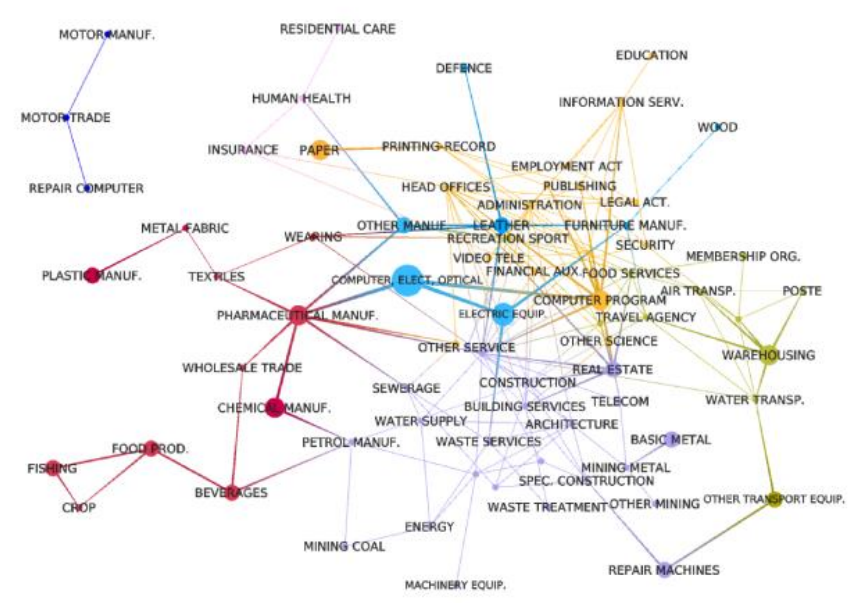

\section{Closest activities} (Louvain clustering)

Administration, education and entertainment

Transports

Manufacturing

Energy, construction,

Financial services

Health \& Insurance

Motor industry

Food, textile, pharmaceutical

Proximity between

activities: $\cos >0.001$

Number of multinational firms

(c) Swerts, Rozenblat, Bida, 2018

Source of data:

ORBIS, BVD, 2016 \& UNIL, 2018

Figure 7: Activity space of multinational firms in Datong and Zhuhai (China) in 2016

Datong (Fig.7-A) used to be the most famous Chinese coal city (in the Shanxi province at North of China), producing few years ago, $40 \%$ of the total Chinese coal needs, but now displaced by the mines of the neighbor region of Inner Mongolia. Besides, Datong has a large transportation activity which is not close to mining in the Chinese average activity space, but for exporting coal, transport is of course essential. In order to face a predicable future crisis, the former mayor Geng Yanbo attracted new investors, developing a new sector around pharmaceutical industry, a new university but also launching circular economy in doing construction materials from coal powder (Tashan Industrial Park). The entire renewal of the old historical town, and the rebuilding of the ancient wall, are still in progress in order to develop tourism that will be supported by the high-speed train from Beijing that will be operational in 2019. Another perspective for Datong is the Belt Road Initiative (BRI) project linking directly Datong to the Western part of China, and further to central Asia until Europe. Despite the mayor has been moved to Beijing in 2013, letting the city with numerous works in progress, and in the meantime the coal price was divided by two, the city continues to renew and a positive dynamic is engaged making still attracting this 3.3 million inhabitants city (Province-city level; 1.6 million in a more restrictive morphological delineation), where hundreds of new buildings are still in progress of construction and where the historic center is now quite totally rebuilt.

Zhuhai is a 1.6 million inhabitants port city in the province of Guangdong, situated in front of Macau. The city benefited three important economic programs: since 1980, a Special Economic Zone, since 1993 a National High-tech Industrial Development Zone and since 2009 the Hengqin New Free Trade zone. Computers, electric activities and pharmaceutical industries were developed, as well as their related 
Rozenblat C. (2021). Cities' systems and networks' proximities: toward a multiplex approach, in Torre A. Gallaud D. (eds.), Handbook on proximity, Chapter 9, Edward Elgar

activities (Fig.7-B). Compared to Datong (Fig.7-A), Zhuhai was much more diversified and continued to do it in the perspective to welcome in 2019 the new bridge linking the city directly to Macau and to Hong-Kong. New buildings are growing everywhere in the city. Its economy is more diversified around its core economic base activities and high services were established for long time by the government in order to support the three economic zones.

These two Chinese examples enlighten the complementarity between the classical "specialization" approach and the "related variety" one, the latter enabling to create very significant material to help decision makers to analyze the situation of the variety and relatedness of activities in their cities, and to orient future policies. The example of the former mayor of Datong also reveals in which extend the right actor at the right place and at the right moment can leverage efficiently territorial development. Social and economic sciences have pinpointed "institutional entrepreneurs" as interfaces and cascade facilitators between heterogeneous social spaces (Padgett \& Powell, 2012). Geng Yanbo, with a strong national network of public and private relations managed to attract strong investors. Either situated in industry or in public institutions, institutional entrepreneurs' actions change a large part of the environment around them, because of the numerous and efficient networks to which they are connected throughout institutional, social, economic, spatial or cognitive networks. It is possible to detect them through some multi-layer networks, where they often appear very connected to a large diversity of networks, then appearing in a strong central position intermediating all the layers, with a minimal proximity to most of them.

\section{Multi-level and multi-dimensional perspective on complex urban systems}

However, the dynamics fostered by the uneven distribution of the innovator networks cannot be reduced to an addition of actors: collective processes occur, that remain difficult to forecast. One can restart from the basic assumption that "high levels of structural social cohesion and interaction between people with similar interest in innovation occur rarely, but when they do occur, the diffusion of ideas within the group and the success of its members are significantly enhanced compared to isolated individuals or groups with lesser cohesion" (White, 2009: 156). The issue is thus to capture these evolutive structural cohesions, forming specific proximities in networks, and their collective formations and evolutions.

Complex systems are thus useful to better understand such cohesions, as they allow to conceive systems into discrete scales along an axis, where key variables should be distributed discontinuously. Self-organizing interactions and processes, such as community-level interactions, are compartmentalized by scale (Lane et al., 2009). Each scale or level organization is decomposed into "structures, processes and functions" (Lane et al., 2009). The structure of the organization at one level describes the parts, and the interactions modalities inside and outside these parts; processes associated with an organization describe its transformations or the transformations to which the organization participates. The function of an organization provides directedness of its actions. These three elements are defined over an evolutive range of spatial and temporal scales or levels.

Following this multi-level hierarchy, in the sense of nested structures, allows defining levels of processes where proximities between actors at the micro-level, define cohesive groups through dense networks at the meso-level structures (or network's clusters). It is possible to define these meso-level structures in the multiple dimensions, sustaining simultaneously and partly independently multiplicative processes resulting in emergence of innovation at the macro level (Fig.8). 
Rozenblat C. (2021). Cities' systems and networks' proximities: toward a multiplex approach, in Torre A. Gallaud D. (eds.), Handbook on proximity, Chapter 9, Edward Elgar

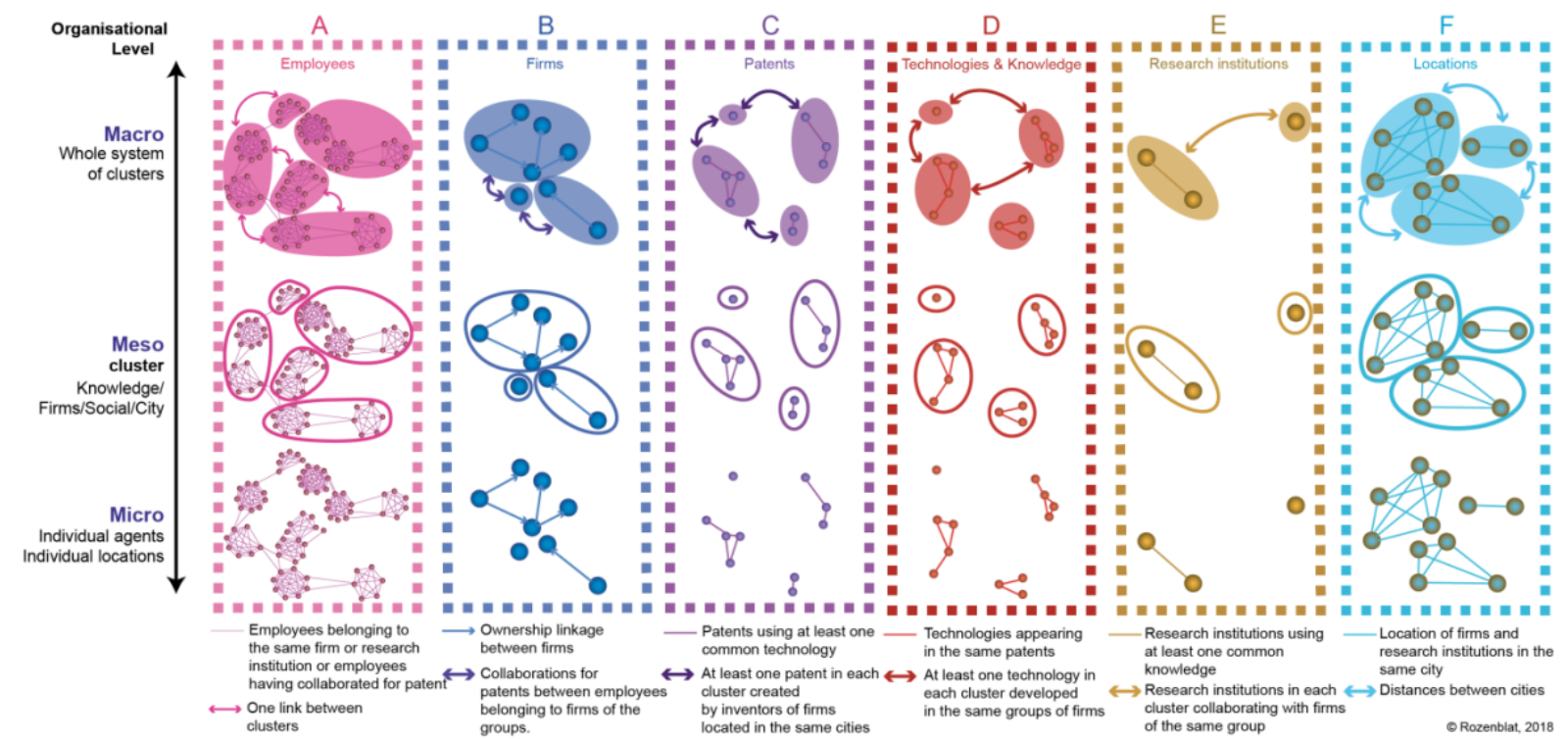

Figure 8: Multi-level and multi-dimensional framework of the innovation networks

Multi-level is the vertical axis; Multi-dimensional is horizontal, expanding each dimension in a multi-

level perspective

In the example of figure 8, the dimension $\mathrm{F}$ of the geographical space reveals that strong proximities between actors located closely, potentially create collective processes at the meso-level (like cities or local cluster) that leverage their position in the global system of cities. Similarly, multi-level systems characterize each dimension: as we saw in section 2.2, technologies form a space defined by their mutual proximities, and similarly, people (employees), firms, research institutions, technologies or patents constitute also their own spaces. In each of them, the micro-entities form some meso-levels of proximity and more dense inter-relations, and the macro-level position mutually these meso-level structures.

These different spaces are partly independent, being structured according to proper logics depending on the actors composing them, on the aims and values sustaining them, on the temporalities that processes need to develop, and on the issues and catastrophes they meet. However, despite their independence, these spaces are widely intertwined, entangled and sometimes juxtaposed forming what is called "heterarchies" in system approaches, because different networks and hierarchies interact all together and because entities might inhabit more than one level, be component of more than one "higher-level» and engage in interactions with entities at a variety of different levels (Latour, 2004). For example, in industrial clusters, the ideal simultaneous proximities in space, in technologies, in institutions and in organizations, foster together the dynamics of such clusters and thus these spaces are superposed. However, this convergence is not always achieved and macro-relations mix with meso or micro ones, creating different degrees of clusters' cohesions.

\subsection{Defining meso-levels}

The conceptual definition of the meso-level is crucial for every dimension, since defining the denser parts of every network leads to categorize actors and to delineate the search of their potential multiplier processes obtained by their mutual exchanges and sharing. Simultaneously, the meso-level gives rise to interactions at the macro-level. This multi-level approach was illustrated and conceptualized in the geographic literature as the "local buzz and Global pipelines" (Amin \& Thrift, 1992; Bathelt et al., 2004) that connect micro networks to macro levels inside the business clusters representing the meso-level. However, once again, the spatial point of view would be incomplete without the other dimensions (cognitive, organizational, social and institutional) (Boschma \& Martin, 2010). In fact, industrial clusters are a good example of the combination of the geographic proximity with the technologic and social ones. Multiple proximities foster exchanges through networks between actors, creating a dependence 
Rozenblat C. (2021). Cities' systems and networks' proximities: toward a multiplex approach, in Torre A. Gallaud D. (eds.), Handbook on proximity, Chapter 9, Edward Elgar

between actors and their networks and even a co-construction of the actors and their networks (White, 2009).

The delineation of the meso-level in each dimension, is central in the study of interdependencies and needs special attention in an interdisciplinary implementation. The Complex System Science literature defines the detection of communities or clusters as the identification of groups of nodes densely connected to each other and sparsely connected to nodes from other clusters (Schaeffer, 2007). First, cluster definition is strongly dependent on the nature of relations and on the measure of the distance or proximities considered in such networks as we underlined it in section 1 (Rozenblat, 2015). Second, numerous algorithms are classified as partitional/hierarchical, divisive/agglomerative, and fuzzy/hard (Jain et al., 1999). Algorithms are also different if they can be applied to directed/undirected networks, weighted/non-weighted networks, or tree-like networks (Fortunato, 2009). In this proliferation of methods, the choice of algorithm is often guided by the nature of data, but also contains numerous choices that remain often very implicit in studies, rending the clustering stage both fuzzy and not reproduceable.

\subsection{Panarchy and adaptive cycles}

In these multi-level perspectives, the "panarchy" approach provides a useful framework to handle such systems (Allen et al., 2014). The panarchy considers different levels of processes through "adaptive cycles" affecting every level, and "cross-scale linkages" which are the processes at one level affecting those at other levels to influence the overall dynamics of the system. The question of proximity arises in the understanding of how and why different networks and the proximities they induce, involve in the adaptive cycles at a certain level and in certain dimension, influencing themselves adaptive cycles of other levels in other dimensions. For example, innovation cycles (either long ones like Kondratieff cycles, either shorter product cycles) interact with cities by their uneven initial distribution and by their diffusion. The spatial diffusion of innovations through urban systems (Pumain et al., 2009; Pumain, 2018) is initiated by the competition between individuals and groups of individuals searching to catch innovation earlier than others in order to benefit of initial advantage (Fig.9).
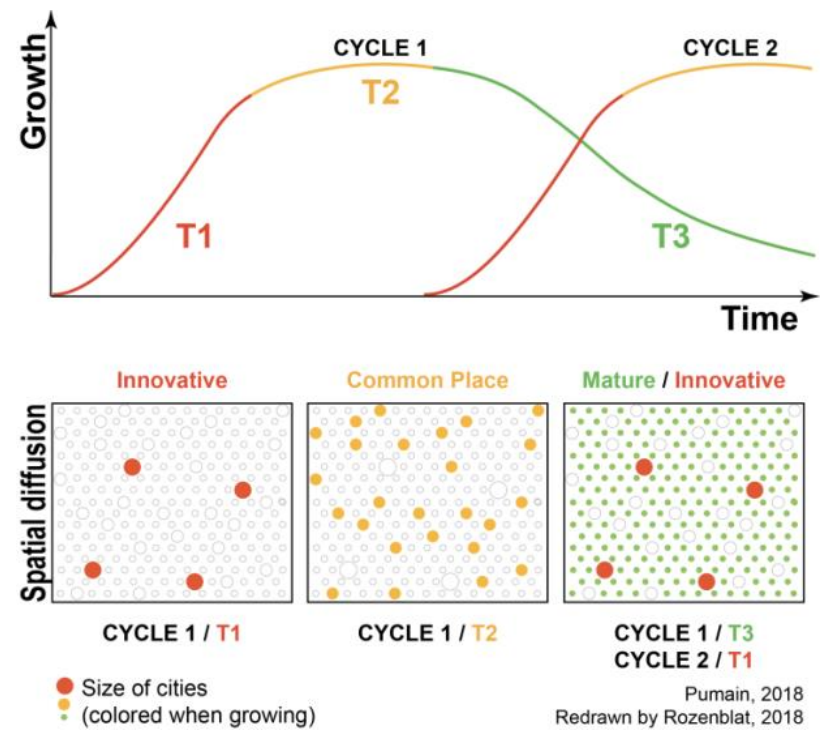

Figure 9: Diffusion cycles in urban systems

At the early stage of an innovative cycle (T1), the new invention is often concentrated in largest cities which corresponds to a rapid exploitation and sequestering of resources (Holling, 1986). Despite the highest costs to locate in large cities, the search of rapid growth and strong support by a diversity of related industries and services favor this concentration (Duranton \& Puga, 2001). Once consolidated, 
Rozenblat C. (2021). Cities' systems and networks' proximities: toward a multiplex approach, in Torre A. Gallaud D. (eds.), Handbook on proximity, Chapter 9, Edward Elgar

the innovation follows a second stage (T2) of diffusions among other cities, until its decrease of growth and value (sometimes collapse) during a third stage of becoming "banal) (T3) leaving the large and medium size cities to benefit the smaller places like cities and towns. This third stage is also the opportunity for novel recombination and shift to the release of a new regime (T1 - cycle 2) that concentrates again in largest cities that have free space let by the previous diffusion of innovation wave.

This "hierarchical diffusion of innovation" implies two complementary evolutions (Pumain et al., 2009):

- First, large cities generally benefit more from innovation waves than smaller ones, because they most often host the early stages when added values are the highest;

- Second, once a territory is stabilized under a political control, the whole urban system (from large to small and medium size cities) evolves according to a distributed growth (Gibrat, 1931; Gabaix, 1999; Pumain, 2006).

The consequences are on one hand, the co-evolution of cities and on the other hand an allometric growth of cities leading to a relative stability of the hierarchy of cities (Pumain et al., 2009) (Fig.10).

A- Co-evolution of US cities' economic profiles since 1970

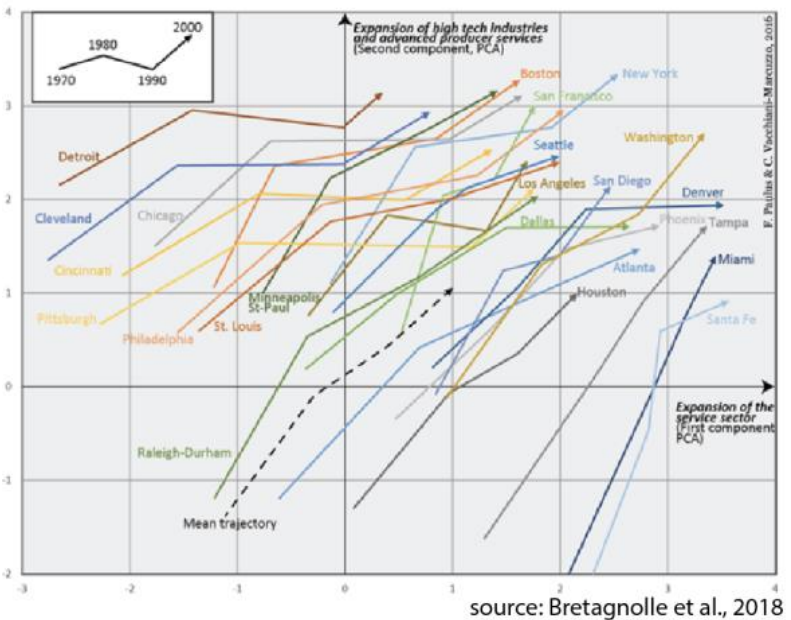

B- Evolution of the US cities' rank size since 1800

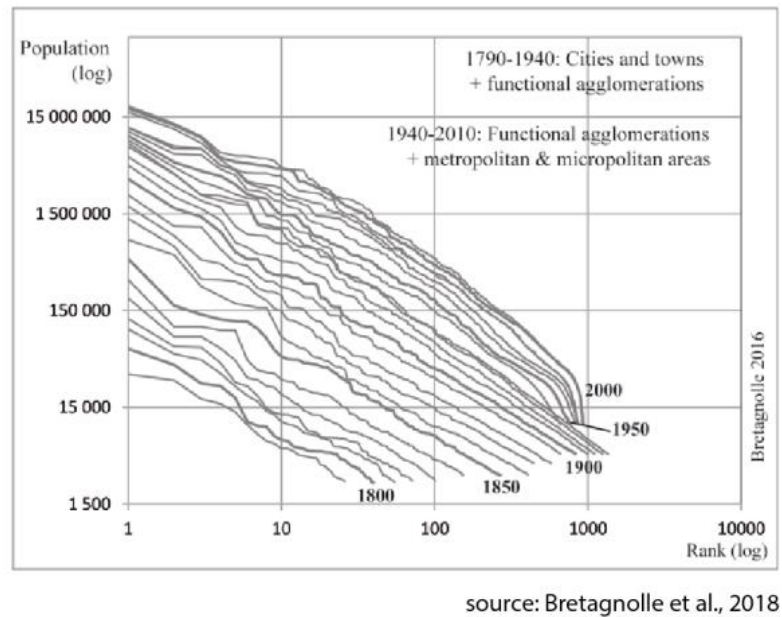

Figure 10: Co-evolution of cities and stability of urban systems' hierarchies

In fact, because of these inter-urban diffusions and because of the multitude of interflows of information, goods and people, cities' activities' profiles co-evolve as it is illustrated for USA (Fig.10-A), and this co-evolution is an evidence for every system of cities with a stable political control (Bretagnolle et al., 2009; Pumain et al., 2009; Bretagnolle et al., 2018). These flows take their origin at the microlevel of actors, and they remain inside cities if they are principally drawn on spatial proximities, or they spread among cities if they are based on other kinds of proximities. Because nowadays activities, industries, social and family networks do not restrain to unique places, most of these micro-networks are inter-urban and thus participate to inter-urban diffusions. In particular, inside the global division of labor, numerous dynamics diffuse from cities to other ones by multinational firms. In this perspective, external networks nourish the local ones of each city which are strengthened, and in feed-back are able to extend through external scopes. This led Doreen Massey (2007) to claim about London that "the local is not only the product of the global, but that global itself is produced in local places » (p.107).

The relative stability of the system of cities induced by the "distributed growth" (Fig.10-B) can be explained by the constant competition existing between actors located in different cities: there is a "competition to capture resources and innovation, so they can continue to make good use of what they have already acquired and maintain or increase their influence within the city systems with which they entertain relationships" (Bretagnolle et al., 2009: 215). This distributed growth which is well known as the "Gibrat law" (Gibrat, 1931), which demonstrates the random growth of cities according to their size 
Rozenblat C. (2021). Cities' systems and networks' proximities: toward a multiplex approach, in Torre A. Gallaud D. (eds.), Handbook on proximity, Chapter 9, Edward Elgar

(Pumain, 1982; Gabaix, 1999), corresponds to one of the key principles of the panarchy approach: the system conservativeness during its scaling up (Allen et al., 2014).

However, some deviations of the Gibrat law are often detected with a tendency on long periods of time of the increase of the cities' hierarchy (Bretagnolle et al., 2009; Pumain, 2018). It was already explained by the initial advantage that largest cities could bring from being the incubator place of the innovation. This advantage is now commonly evaluated by the "scaling laws" parameter $\beta$, measuring at a certain period of time, the degree of the dispersion of an activity among cities according to their size (Pumain et al., 2006; Bettencourt et al., 2007; Pumain et al., 2009; Pumain \& Rozenblat, 2018). Innovative activities always appear as "supra-linear" distributed $(\beta>1)$, revealing an over-concentration in large cities. Thus, after diffusing among common places when activities become less innovative, the hierarchy of cities according to the activities decreases towards a "sub-linear" distribution $(\beta<1)$.

Each economic wave impulses a new energy of growth inside the urban system, where organizations of people, firms and institutions react according to their integrative capability during this scaling up. The scaling up corresponds to specific periods, as described by White (2009) about the emergence of biotech in the Silicon Valley:

\begin{abstract}
"Emergent organizational couplings between complementary firms resulted in rapid emergence of a single broad structurally cohesive core of organizations linked through collaborative ties in a division of labor, including capital and marketing. In so doing, core organizations in the fields benefited from broader diffusion of knowledge but, by bringing new recruits into a mixing process for new knowledge potentials and skills, also managed to prevent stultification that could result from sharing and homogenization. This involved a dynamic of periods of heavy recruitment of newcomers alternating with periods that focused on integration of knowledge as between new recruits and established practitioners" (White, 2009: 172).
\end{abstract}

This description of an emergent phase highlights how much the main challenge during each release period of innovation wave, is to maintain or to rebuild a high degree of structural cohesion and proximity between the system's components. In relation with our discussion on the entangled proximities from different dimensions, relatedness of activities inside each city (so in a geographic proximity) in this context of successive waves, reveals the capacity of urban actors' organizations (individuals, firms and institutions), during an emerging cycle, to develop close activities in the space of technologies. Thus, relatedness is both produced by two processes:

- by the traces of the successive adoption of different innovation waves, up to variable levels of specialization in the activities that were developed (Frenken \& Boschma, 2007) defining the potential of local actors to catch, to develop innovation and to position in the global division of labor.

- by the capacity of actors and firms to adapt and sustain local complementary activities. At the contrary, too much rigidity of the local place in cities (lock-in at the meso level) can create a strong break in the city's attractiveness and transformation (Grabher, 1993). In this respect, Farinha et al. (2019) showed how much local synergies ${ }^{7}$ inside US Metropolitan Statistical Areas (MSAs) had a strong effect on the growth of jobs, higher than jobs' skills similarity or jobs' complementarity in the value chains.

\title{
3.3 Micro/meso/macro cross-level linkages
}

\footnotetext{
${ }^{7}$ Job synergies are jobs' relatedness calculated according to their co-location in the same MSAs without any mutual effect of skills' similarity neither value chains' complementarity.
} 
Rozenblat C. (2021). Cities' systems and networks' proximities: toward a multiplex approach, in Torre A. Gallaud D. (eds.), Handbook on proximity, Chapter 9, Edward Elgar

Each level creates its own context interacting to the other levels, through what is called "cross-scale linkages" in the panarchy approach (Allen et al., 2014). During reorganization at a given scale, top-down interactions of conservative structures at larger scales provide a form of memory that encourages reorganization around the same structures and processes, rather than a different set. Similarly, during reorganization phases, "destructive" processes can affect larger scales in a bottom-up direction corresponding to a "revolt" in social events. In these multi-level and multi-dimensional systems, cascades occur across the different networks and dimensions (Kitzak et al., 2010), involving multiple interacting cycles and creating emergent structures resulting either from top-down dynamics by an influential policy, either from agents' interactions bottom-up processes (Rozenblat, 2012). In a bottom up direction, micro behaviors as "sharing, matching and learning" (Duranton \& Puga, 2004) create all together, agglomeration economies at the meso-level (Fujita et al., 2000; Rosenthal \& Strange, 2001; Parr, 2002). Individual competition plays a crucial role leading to a selection process (Nelson \& Winter, 1982; Essletzbichler \& Rigby, 2010), but the factors selecting the final "winners" in society are not totally explained by the market competition (Padgett \& Powell, 2012).

Emerging organizations in geographic spaces, in sectors or communities can either come from human initiative and will as policy actions, training, formation of clubs, corporations or associations, either they can be spontaneous self-organized processes without any awareness. These self-organized processes emerge from properties like transitivity (Uzzi, \& Gillespie, 2002) local buzz (Storper \& Venable, 2004) or indivisible mass effects (Bathelt \& Glückler, 2011; Porter, 1998). It is in the collective processes at the meso-level, in whatever dimension it is, that multiplier effects strengthen the capacity of each actor to develop global linkages (Rozenblat, 2010).

In a top down point of view, while each single person has got his / her own relational history, the multiple meso-levels (in the different dimensions) contain the whole history of interactions (previous interactions or accessibility or routines, all producing proximity). These meso-levels provide the pathways whereby agents move into the future (Lane, 2006). Holland (1998) proposed that the mesolevel also contains the locus of process functionality producing the sense and values of individual or collective actions. In this way, the meso-level contains some conservative structures providing $a$ memory that encourages reorganization around the same structures and processes. It often also contains resilience properties defined originally as "persistence of systems and of their ability to absorb change and disturbance and still maintain the same relationships between populations or state variables" (Holling, 1973: p.14).

The macro-level, by definition, interlinks the meso-level "clusters" each other with weaker interactions than inside clusters (i.e.: clusters can be defined in the several dimensions of proximities and between different kinds of object/subject: between cities, between activities or between communities etc...). Despite connections (and thus proximities) are weaker at this macro-level than inside clusters, the topdown interactions from the global level are very strong, because they contain the sectorial global conditions influencing cluster formations at the meso level. External macro or meso factors leverage innovation emergence and spillovers that often operate through specialized networks at international, national or regional scales. Here also, this macro-level tends to maintain a certain stability on the meso and micro levels, through the multi-interdependencies (and thus, proximity) that it contains. We saw in section 3.2 how much urban systems are quite stable, despite the strong affections they permanently receive from the economic cycles: diffusion from cities to another ones (at micro/macro levels) constrains the meso-city structures to adapt and evolve. Despite that all cities permanently renew, the ones belonging to the same system (as national system or if they have similar specializations) are closer each other in their institutional or economic dimensions and they tend to evolve similarly. Thus, cities maintain their identity, as well as their respective positions vis-a vis other cities. This resilience capacity of urban systems is thus a multi-level property. 
Rozenblat C. (2021). Cities' systems and networks' proximities: toward a multiplex approach, in Torre A. Gallaud D. (eds.), Handbook on proximity, Chapter 9, Edward Elgar

\subsection{Multi-dimensional and multi-level linkages implementations}

The implementation of the combination of processes in different dimensions are straightforward applicable in a network approach, rendering multi-layer methodologies essential to enable encompassing all the potential diffusing processes through actors and artifacts. Statistical properties describe these networks in their static and dynamic multidimensional aspects.

Research in multilayer approaches makes now possible to implement centrality indexes simultaneously in the different dimensions (Kurant \& Thiran, 2006; Kivelä et al., 2014; Boccatelli et al., 2014; Gomez et al., 2018). With various multilayer centrality indexes, Gomez et al. (2018) underlined how much "The calculation of centrality in several empirical multilayer interconnected networks shows that the highly ranked nodes are not those with large importance in the aggregated network or in individual layers, but the nodes responsible of the cohesion of the whole structure, bridging together different types of relations" (Gomez et al., 2018: 28). They call this new property "versatility", which qualifies nodes acting specifically in what we called earlier "structural cohesion". Versatility allows identify the specific "institutional entrepreneurs" facilitating diffusions between the heterogeneous social spaces as defined in section 2.3.

Concerning the transmissions inside or between levels and dimensions, the "first law of geography" that was described seminally by Tobler (1975) as "everything is related to everything but closer things are more related than farer things" is not dead. It has been applied with success on innovation networks (Maggioni et al., 2007) and on multinational firms (Rozenblat, 2015). Going further, this gravitation models can be tested for every dimension, and thus could be applied for all kinds of objects and their proximities in several spaces: technologies according to their relatedness, people through social networks, institutions, geographic space, firms through their activities... In their classical implementations, these models were supported by classic parametric statistics assuming independence between subjects that are no more adapted to individuals and artifacts that are mostly mutually dependent. These gravitational models have been recently rediscovered by physicists in socio-economic domains (Barthelemy, 2011) and readapted in more sophisticated networks models (Simini et al., 2012). They can be applied in whatever dimensions one can conceive, with some relevant adapted metrics: In consequence, gravitation models could be implemented beyond the spatial dimension in all the other cognitive, social, institutional and organizational dimensions, but also in a combination of them.

In the multi-dimensional space, the resilience property can be addressed by disturbing the network, and afterwards measuring the network's potential of facilitating information propagation. For example, the Susceptible-Infected-Recovered (SIR) diffusion model, which originally was developed to simulate virus spreading (Anderson et al., 1992; Diekmann et al., 2000), has also been applied to simulate spreading of crises on economic networks (Garas et al., 2010) and information spreading (Kitsak et al., 2010).

In order to explain the dynamics of a network's structure, sociologists proposed Exponential Random Graph Models (ERGM) calibrating a stochastic process of edges creation against observed networks. Until now, this approach was mainly applied on non-weighted graphs and offers tests of network's patterns like stars or transitive triangles (Lusher et al., 2013). However, it can also integrate external "environmental" or nodal variables, leading to the verification of the Core/periphery models on knowledge networks (Balland et al., 2010). Recent extensions supporting weighted and directed networks, would enable to integrate different kinds of variables on nodes or on edges (Krivitsky, 2012), making possible to develop gravitation models coupled with ERGM. As far as we know, these extensions have not yet been tested on innovation networks.

In addition, the use of STERGM (Separate Temporal ERGM) enables to model network dynamics in discrete time. By operating calibration of ERGM models encapsulating clusters properties used as configuration statistics, it is possible to underline the effect of the meso-level (for example structure 
Rozenblat C. (2021). Cities' systems and networks' proximities: toward a multiplex approach, in Torre A. Gallaud D. (eds.), Handbook on proximity, Chapter 9, Edward Elgar

characteristics or attributes of clusters' relatedness) on micro-level dynamics (major actor or link's creation/destruction). Applied to real innovation networks, STERGM could describe clusters dynamics by outlining meso-level structural properties that foster link formation or destruction between individual actors. For example, the co-patenting relation is likely to last with the updating of the patent or with new patents, or is likely to not be reiterated. In this example, we consider temporal cycles in innovation networks (Padgett \& Powell, 2012) in interaction with meso-level variables. More generally, one can apply techniques used in Recommender Systems research, in order to identify potential connection among individuals, portions of networks (clusters) or entire systems. The techniques, based on existing connections of innovation will suggest new ones that can be assessed for further utility in the whole system (Ricci et al., 2011).

\section{Using proximity in multi-level and multi-dimensional networks to define policies}

The ultimate goal of all these methods would be to elaborate, thanks to networks' proximities, policies supporting either inventors, either firms, either specific patent or technology, or even cities or countries, and to estimate their potential spreading effects on the whole complex system. In fact, through the diffusions, transmissions and interdependencies facilitated by proximities in all these multidimensional and multi-level interdependent networks, one assumes that policies can have indirect and amplified effects. For example, national sectorial policies (macro-level) affect principally cities and regions (meso-level) that host them (through top-down cognitive and spatial proximities); or the support of certain firms (micro-level) can strength entire related sectors affecting both these whole sectors and also the meso cities and the system of cities they belong to, through bottom-up processes.

Despite that today, numerous platforms offer graphical displays for innovation mapping, "business clusters" are still viewed by stakeholders as local entities and policy makers act only on specific domains and scales. The sectorial policies could certainly gain in being elaborated in this multi-dimensional network perspective. The question becomes to identify the key nodes or groups to target policies by evaluating the potential cascading indirect effects of these policies on other kinds of actors or artifacts, through networks relying them. Situating each policy at its level and at its dimension of intervention, could allow using complex systems in order to simulate their potential effects (Tab.1).

Table 1: Taxonomy of innovation policy tools and their actions on different system levels

\begin{tabular}{|c|c|c|c|c|c|c|c|}
\hline \multirow{2}{*}{\multicolumn{3}{|c|}{$\begin{array}{l}\text { POLICY TOOLS } \\
\text { (Concrete actions are indicated as examples) }\end{array}$}} & \multicolumn{5}{|c|}{ ACTION LEVELS IN PROXIMITIES OF NETWORKS } \\
\hline & & & Nodes & Linkages & Clusters & $\begin{array}{l}\text { Links between } \\
\text { clusters }\end{array}$ & $\begin{array}{c}\text { Whole } \\
\text { structure of } \\
\text { the network }\end{array}$ \\
\hline \multirow{7}{*}{$\begin{array}{l}\text { Supply side } \\
\text { measures } \\
\text { Targeting a } \\
\text { wide range of } \\
\text { actors } \\
\text { producing } \\
\text { different forms } \\
\text { of innovation }\end{array}$} & \multirow{5}{*}{ Finance } & Equity support & Public VC & Crowd funding & & & $\begin{array}{l}\text { Anti-trust } \\
\text { law }\end{array}$ \\
\hline & & Fiscal measures & \multicolumn{2}{|c|}{ Fiscal incentives to R\&D } & \multicolumn{2}{|c|}{ Social incentives } & \\
\hline & & $\begin{array}{l}\text { Support for public } \\
\text { sector research }\end{array}$ & Patenting, to TTOs & $\begin{array}{l}\text { Intermediary } \\
\text { organizations }\end{array}$ & $\begin{array}{l}\text { Cluster based } \\
\text { brokers }\end{array}$ & \begin{tabular}{|l|} 
Inter-cluster \\
relationships \\
\end{tabular} & \\
\hline & & $\begin{array}{l}\text { Support for training } \\
\text { and mobility }\end{array}$ & Support for training & $\begin{array}{l}\text { Recruitment of } \\
\text { engineers or } \\
\text { PhD }\end{array}$ & $\begin{array}{l}\text { Entrepreneur } \\
\text { HIP programs }\end{array}$ & & \\
\hline & & $\begin{array}{l}\text { Grant for industrial } \\
\text { R\&D }\end{array}$ & Grants (incubators) & $\begin{array}{l}\text { TRC and } \\
\text { technical } \\
\text { centres }\end{array}$ & & EUREKA & $\begin{array}{l}\text { Collective } \\
\text { program }\end{array}$ \\
\hline & \multirow{2}{*}{ Services } & $\begin{array}{l}\text { Information \& } \\
\text { Brokerage support }\end{array}$ & Contact DB & $\begin{array}{l}\text { 'Vision } \\
\text { shaping' }\end{array}$ & Wider vision & & \\
\hline & & $\begin{array}{l}\text { Networking } \\
\text { measures }\end{array}$ & & $\begin{array}{l}\text { Support for } \\
\text { alliances }\end{array}$ & "Clubs" & $\begin{array}{l}\text { Cross- } \\
\text { cooperation }\end{array}$ & \\
\hline \multicolumn{3}{|c|}{$\begin{array}{l}\text { Systemic policies } \\
\text { Making a real public/private systemic }\end{array}$} & Business acts & & IPR, standards & & $\begin{array}{l}\text { Migration } \\
\text { policies }\end{array}$ \\
\hline \multirow{3}{*}{$\begin{array}{l}\text { Demand side } \\
\text { measures } \\
\text { Public and } \\
\text { private demand }\end{array}$} & \multicolumn{2}{|c|}{ Regulation } & $\begin{array}{l}\text { Decentralization of } \\
\text { state services }\end{array}$ & $\begin{array}{l}\text { Transport } \\
\text { infrastructures }\end{array}$ & & & \\
\hline & \multicolumn{2}{|c|}{ Public procurement } & & & \multicolumn{3}{|c|}{ Stimulation of markets } \\
\hline & \multicolumn{2}{|c|}{ Support of private demand } & Demand subsidies & & \multicolumn{3}{|c|}{ Subsidies or fiscal policies } \\
\hline
\end{tabular}


Rozenblat C. (2021). Cities' systems and networks' proximities: toward a multiplex approach, in Torre A. Gallaud D. (eds.), Handbook on proximity, Chapter 9, Edward Elgar

The table 1 proposes supply side, demand side and systemic policies following the typology stressed by Edler \& Georghiou (2007). This typology was completed here by the elements of the three levels described along this article: for the micro level: nodes, linkages; for the meso-level: cluster; for the macro-level, linkages between clusters or policies concerning the whole system. These levels of implementation can qualify policies applied in whichever dimension. We illustrated them by examples being mostly taken in the European Union. The multi-level framework permits to show all the possible policies implementations, and make clearer the huge number of initiatives.

We do not pretend here listing all the possible policies, but putting together different policies in an ordered grid, may question their cross-level and cross-dimensional potential consequences. These consequences depend widely on the entangled cycles of dimensions and levels on each context and on the manner, policies are undertaken (Janssen \& Frenken, 2019). For each policy, the questions of its effectiveness, its force field, its possible counter-intuitive effects and its limits, remain open. Far to address the whole system, this framework could partially question the strength that each policy must have in order to reach, in specific situations, the tipping point of mass effect enabling to achieve the expected dynamics. The main issue appears in the complex combinations of policies applied in different dimensions and at different levels: How can interact different policies applied on different parts of the networks and which could be the most effective combination requiring less investment?

\section{Conclusion}

In this chapter, we questioned the relation between city and proximity with a multilayer framework proposed by the complex system science enabling to integrate the multi-dimensional contribution of the Evolutionary Economic Geography with the multi-level Evolutionary Systems of Cities. Although the two approaches converge in considering the dynamics of interactions at the core of the systems' evolutions, and proximity and cohesion as facilitators of these interactions, they differ in their deep conception of economic cycle diffusions and evolutionary selections. We nevertheless think that their combination is possible with a clear definition of the actors (in a very wide sense), of their inter-relations, and with rigorous methodologies highlighting the properties of the evolutive (meso and macro) levels of organization they constitute in several dimensions of proximities.

The role of the interactions functions is however central in each dimension, underlying the ways actors contribute to renew their proximities through some actions that mutually transform them. In fact, following Norbert Elias (1991) and applying it to cities, individuals and artifacts create new proximities through new interaction rules that reconfigure cities. Thus, proximities for the renewal of cities are much more than factors and explanations: they are part of the actions and strategies inserted into the self-representation of the urban society on which research can open new perspectives.

\section{References:}

Akrich, M. (2006). Les objets techniques et leurs utilisateurs de la conception à l'action. Sociologie de la traduction. Textes fondateurs, 179-199.

Aldrich, H., \& Whetten, D. A. (1981). Organization-sets, action-sets, and networks: Making the most of simplicity. Handbook of organizational design, 1, 385-408.

Allen, C. R., Angeler, D. G., Garmestani, A. S., Gunderson, L. H., \& Holling, C. S. (2014). Panarchy: theory and application. Ecosystems, 17(4), 578-589

Amin, A., \& Cohendet, P. (2004). Architectures of knowledge: Firms, capabilities, and communities. Oxford University Press

Amin, A., \& Thrift, N. (1992). Neo-Marshallian Nodes in Global Networks*. International Journal of Urban and Regional Research, 16(4), 571-587.

Anderson, B., \& McFarlane, C. (2011). Assemblage and geography. Area, 43(2), 124-127. 
Rozenblat C. (2021). Cities' systems and networks' proximities: toward a multiplex approach, in Torre A. Gallaud D. (eds.), Handbook on proximity, Chapter 9, Edward Elgar

Anderson, R. M., May, R. M. \& Anderson, B. (1992). Infectious Diseases of Humans: Dynamics and Control (Oxford Science Publications, 1992).

Audretsch, D. B., \& Feldman, M. P. (1996). R\&D spillovers and the geography of innovation and production. The American economic review, 86(3), 630-640.

Balland, P. A., Boschma, R., \& Frenken, K. (2015). Proximity and innovation: From statics to dynamics. Regional Studies, 49(6), 907-920.

Balland, P.-A., Suire, R., \& Vicente, J. (2010). How do Clusters/Pipelines and Core/Periphery Structures Work Together in Knowledge Processes? Papers in Evolutionary Economic Geography, 10.

Barthélemy, M. (2011). Spatial networks. Physics Reports, 499(1), 1-101

Bathelt, H., \& Glückler, J. (2011). The relational economy: geographies of knowing and learning. Oxford: Oxford University Press.

Bathelt, H., Malmberg, A., \& Maskell, P. (2004). Clusters and knowledge: local buzz, global pipelines and the process of knowledge creation. Progress in Human geography, 28(1), 31-56.

Battiston S., Caldarelli G., Garas A. (eds.) (2018). Multiplex and multi-layer networks, Oxford University Press, 180p. Batty M. (2007). Cities and Complexity: Understanding Cities with Cellular Automata, Agent-Based Models, and Fractals. MIT Press

Bettencourt, L. M., Lobo, J., Helbing, D., Kühnert, C., \& West, G. B. (2007). Growth, innovation, scaling, and the pace of life in cities. Proceedings of the national academy of sciences, 104(17), 7301-7306.

Boccaletti, S., Bianconi, G., Criado, R., del Genio, C. I., Gómez-Gardeñes, J., Romance, M., Zanin, M. (2014). The structure and dynamics of multilayer networks. Physics Reports, 544(1), 1-122.

Bonacich, P. (2007). Some unique properties of eigenvector centrality. Social networks, 29(4), 555-564.

Borgatti, S. P., \& Everett, M. G. (1992). Notions of position in social network analysis. Sociological methodology, 1 35.

Boschma R. (2005). Proximity and innovation: a critical assessment. Reg Stud 39:61-74

Boschma, R., \& Frenken, K. (2010). The Spatial Evolution of Innovation Networks: A Proximity Perspective. In The handbook of evolutionary economic geography. Edward Elgar Publishing.

Boschma, R., \& Martin R. (eds.) (2010). The handbook of evolutionary economic geography. Edward Elgar Publishing.

Bouba-Olga, O., \& Grossetti, M. (2008). Socio-économie de proximité. Revue d’Economie Régionale Urbaine, (3), 311-328.

Breschi, S., \& Lissoni, F. (2004). Knowledge networks from patent data. In Handbook of quantitative science and technology research (pp. 613-643). Springer, Dordrecht.

Breschi, S., \& Lissoni, F. (2005). "Cross-Firm" Inventors and Social Networks: Localized Knowledge Spillovers Revisited. Annales d'Economie et Statistique, 189-209.

Bretagnolle A., Pumain D., Vacchiani-Marcuzzo C. (2009). The organization of Urban systems, in Lane D., van der Leeuw S., Pumain D., West G., Complexity perspectives in innovation and social change, methodos series 7. 197220

Cai D., Shao Z., He X. , Yan X., and Han J. (2005). Community mining from multi-relational networks. In Proceedings of the $9^{\text {th }}$ European Conference on Principles and Practice of Knowledge Discovery in Databases

Callon, M. (1986). Éléments pour une sociologie de la traduction: la domestication des coquilles Saint-Jacques et des marins-pêcheurs dans la baie de Saint-Brieuc. L'Année sociologique (1940/1948-), 36, 169-208

Cassi L. \& Plunket A. (2014). Proximity, network formation and inventive performance: in search of the proximity paradox, Ann Reg Sci 53:395-422

Castells, M. (2013). Communication power. Oxford University Press.

Cattan, N., Pumain, D., Rozenblat, C., Saint-Julien, Th. (1999). Le système des villes européennes. Anthropos. Coll. villes.

Content, J., \& Frenken, K. (2016). Related variety and economic development: a literature review. European Planning Studies, 24(12), 2097-2112.

Contractor, N. (2009). The emergence of multidimensional networks. Journal of Computer-Mediated Communication, 14(3), 743-747. 
Rozenblat C. (2021). Cities' systems and networks' proximities: toward a multiplex approach, in Torre A. Gallaud D. (eds.), Handbook on proximity, Chapter 9, Edward Elgar

Contractor, N., Monge, P., \& Leonardi, P. M. (2011). Network Theory. Multidimensional networks and the dynamics of sociomateriality: bringing technology inside the network. International Journal of Communication, 5, 39.

Dicken P., Kelly P. F., Olds Kr., Wai-Chung Yeung H. (2001). Chain networks, territories and scales: toward a relational framework for analysing the global economy. Global Networks 1, 89-112.

Diekmann, O. \& Heesterbeek, J. A. P. (2000). Mathematical Epidemiology of Infectious Diseases: Model Building, Analysis and Interpretation, Wiley Series in Mathematical \& Computational Biology.

Duranton, G., \& Puga, D. (2004). Micro-foundations of urban agglomeration economies. Handbook of regional and urban economics, 4, 2063-2117.

Edler, J., \& Georghiou, L. (2007). Public procurement and innovation - Resurrecting the demand side. Research policy, 36(7), 949-963.

Farinha, T., Balland, P. A., Morrison, A., \& Boschma, R. (2019). What drives the geography of jobs in the US? Unpacking relatedness. Industry and Innovation, 1-35.

Fleming, L., King III, C., \& Juda, A. I. (2007). Small worlds and regional innovation. Organization Science, 18(6), 938954.

Foray, D. (2014). Smart Specialisation: Opportunities and Challenges for Regional Innovation Policy (Vol. 79). Routledge.

Fortunato S (2009) Community detection in graphs. Physics Reports, Elsevier, 2010, 486, 75-174.

Frenken, K., Van Oort, F., \& Verburg, T. (2007). Related variety, unrelated variety and regional economic growth. Regional studies, 41(5), 685-697.

Gabaix, X. (1999). Zipf's law for cities: an explanation. The Quarterly journal of economics, 114(3), 739-767.

Garas A., Argylakis P., Rozenblat C., Tomassini M., Havlin S. (2010). Worldwide spreading of economic crisis, New Journal of Physics 12 - 113043

Giddens A. (1984). The constitution of society. Polity Press - Basil Blackwell

Gomez S., De Domenico M., Sole-Ribalta A., Omodei E. and Arenas A. (2018). Multilayer networks, in Battiston S., Caldarelli G., Garas A. (eds.) (2018). Multiplex and multi-layer networks, Oxford University Press, 3-21

Grabher, G. (Ed.) (1993) The Embedded firm: On the Socio-economics of Industrial Networks. London: Routledge. Henderson V., A. Kuncoro \& Turner M. (1995). Industrial development in cities, Journal of Political Economy, 103/5: 1067-1090.

Holland J. (1998). Emergence: from chaos to order, Addison-Wesley, Reading.

Holling, C. S. (1986). The resilience of terrestrial ecosystems: local surprise and global change. Sustainable development of the biosphere, 14, 292-317.

Jaffe A-B. (1986). Technological Opportunity and Spillovers of R \& D: Evidence from Firms' Patents, Profits, and Market Value, The American Economic Review, Vol. 76, No. 5 (Dec., 1986), pp. 984-1001

Jaffe, A. B., Trajtenberg, M., \& Henderson, R. (1993). Geographic localization of knowledge spillovers as evidenced by patent citations. the Quarterly journal of Economics, 108(3), 577-598.

Jaffe, A. B. (1989). Real effects of academic research. The American economic review, 957-970.

Jain AK, Murty MN, Flynn PJ (1999) Data clustering: a review. ACM Comput Surv 31(3):264\{323\}.

Janssen, M. J., \& Frenken, K. (2019). Cross-specialisation policy: rationales and options for linking unrelated industries. Cambridge Journal of Regions, Economy and Society, 12(2), 195-212.

Kirman, A., \& Zimmermann, J. B. (Eds.). (2012). Economics with heterogeneous interacting agents (Vol. 503). Springer Science \& Business Media.

Kivelä, M., Arenas, A., Barthelemy, M., Gleeson, J. P., Moreno, Y., \& Porter, M. A. (2014). Multilayer networks. Journal of complex networks, 2(3), 203-271.

Kitsak, M., Gallos, L. K., Havlin, S., Liljeros, F., Muchnik, L., Stanley, H. E., \& Makse, H. A. (2010). Identification of influential spreaders in complex networks. Nature Physics, 6(11), 888-893.

Krivitsky, P. N. (2012). Exponential-family random graph models for valued networks. Electronic Journal of Statistics, 6, 1100.

Kurant, M., \& Thiran, P. (2006). Layered Complex Networks. Physical Review Letters, 96(13), 138701. 
Rozenblat C. (2021). Cities' systems and networks' proximities: toward a multiplex approach, in Torre A. Gallaud D. (eds.), Handbook on proximity, Chapter 9, Edward Elgar

Lane D. (2006). Hierarchy, complexity, society, in Pumain D. (ed.) Hierarchy in natural and social science, Springer Methodos series 3, 81-119

Lane D., Maxfield R., Read D., van der Leeuw S. (2009). From population to organization thinking, in Lane D., van der Leeuw S., Pumain D., West G., Complexity perspectives in innovation and social change, methodos series 7. 1141

Law, J., \& Hassard, J. (1999). Actor network theory and after. Wiley-Blackwell

Lazega, E., Jourda, M. T., Mounier, L., \& Stofer, R. (2008). Catching up with big fish in the big pond? Multi-level network analysis through linked design. Social Networks, 30(2), 159-176.

Lennert M, Van Hamme G., Rozenblat C., Pumain D. (2011). FOCl : Future Orientation of Clties, European Spatial Planning Organization Network, ESPON reports

Liebowitz, S. J.,Margolis. S.E. (1995). Path dependence, lock-in, and history. JL Econ. \& Org. 11: 205.

Lundvall, B. Å., \& Maskell, P. (2000). Nation states and economic development: from national systems of production to national systems of knowledge creation and learning. Oxford University Press.

Lusher, D., Koskinen, J., \& Robins, G. (2013). Exponential Random Graph Models for Social Networks. Cambridge: Cambridge University Press.

McFarlane C (2009). Translocal assemblages: space, power and social movements, Geoforum, 40, 561-7

Marcus G. E. \& Saka E. (2006). Assemblage, Theory, Culture \& Society 23 101-9

Massard, N.\& Mehier, C. (2010), Proximity and Innovation. Through an "Accessibility to Knowledge" Lens. Reg. Studies, 43, 1, pp.77-88

Maggioni MA, Nosvelli M, Uberti TE (2007). Space versus networks in the geography of innovation: a European analysis. Pap Reg Sci 86(3):471-493

Massey, D. (2007). World City, Polity Press. Cambridge.

Monge, P. R., Contractor, P. S., \& Contractor, N. S. (2003). Theories of communication networks. Oxford University Press, USA.

Müller, M. (2015). Assemblages and actor-networks: Rethinking socio-material power, politics and space. Geography Compass, vol. 9, no 1, p. 27-41.

Nelson, R. R. (1993). National innovation systems: A comparative study. Oxford university press, Oxford

Padgett, J. F. \& Ansell, C. K. (1993). Robust action and the rise of the medici, 1400-1434. American Journal of Sociology, pages $1259\{1319$.

Padgett J.F. \& Powell W.W. (2012). The problem of emergence, in Padgett J.F., Powell W.W. The Emergence of organizations and Markets, Princeton University Press, 1-29

Phillips J. (2006). Agencement/assemblage Theory, Culture \& Society 23108

Poole, M. S., \& Contractor, N. S. (2012). Conceptualizing the multiteam system as an ecosystem of networked groups. In S. J. Zaccaro, M. A. Marks, \& L. A. DeChurch (Eds.), Multiteam systems: An organizational form for dynamic and complex environments (pp. 193-224). New York, NY: Routledge Academic.

Porter, M. E. (1998). Clusters and the new economics of competition (Vol. 76). Harvard Business Review Watertown.

Powell W., White D., Koput K., Owen-Smith J. (2005). Network Dynamics and Field Evolution: The Growth of Interorganizational Collaboration in the Life Sciences. American Journal of Sociology 110(4):1132-1205

Pumain, D. (1982). La dynamique des villes. Economica.

Pumain D. (2018). An Evolutionary Theory of Urban Systems, in Rozenblat C., Pumain D., Velasquez E., International and transnational perspectives on Urban systems, Springer / Advances in geographical and environmental sciences, 3-18

Pumain, D., Paulus, F., Vacchiani-Marcuzzo, C., \& Lobo, J. (2006). An evolutionary theory for interpreting urban scaling laws. Cybergeo: European Journal of Geography.

Pumain D., Paulus F., Vacchiani-Marcuzzo C. (2009). Innovation cycles and Urban dynamics, in Lane D., van der Leeuw S., Pumain D., West G., Complexity perspectives in innovation and social change, methodos series 7. 237260

Rallet, A., \& Torre, A. (2017). 26. Geography of innovation, proximity and beyond. The Elgar companion to innovation and knowledge creation, 421. 
Rozenblat C. (2021). Cities' systems and networks' proximities: toward a multiplex approach, in Torre A. Gallaud D. (eds.), Handbook on proximity, Chapter 9, Edward Elgar

Ricci, F., Rokach, L., \& Shapira, B. (2011). Recommender Systems Handbook, Springer.

Roth, C. \& Cointet, J.P. (2010). Social and Semantic Coevolution in Knowledge Networks. Social Networks, 32: 1629.

Rozenblat C. (2012). Villes et réseaux : entre des processus top-down et bottom-up. In Hegron (ed.) La modélisation de la ville : du modèle au projet urbain, Commissariat général au développement durable - Direction de la recherche et de l'innovation, 74-89

Rozenblat C. (2015). Approches multiplexes des systèmes de villes dans les réseaux d'entreprises multinationales, Revue d'Economie Régionale et Urbaine, 3, 393-424.

Rozenblat C. (2015). Inter-Cities' Multinational Firm Networks and Gravitation Model, Annals of the Japanese Association of Economic Geographers, 61, 3, 219-237

Rozenblat C. (2019). Extending the concept of city: delineation of Large Urban Regions (LURs) for the cities of the world, Cybergeo - Data Papers.

Schaeffer S.E. (2007) Graph clustering. Computer Science Review 1(1):27\{64\}

Shutters, S. T., Muneepeerakul, R., \& Lobo, J. (2015). Quantifying urban economic resilience through labor force interdependence. Palgrave Communications, 1, 15010.

Simini, F., González, M. C., Maritan, A., \& Barabási, A. L. (2012). A universal model for mobility and migration patterns. Nature, 484(7392), 96.

Storper, M., \& Venables, A. J. (2004). Buzz: face-to-face contact and the urban economy. Journal of economic geography, 4(4), 351-370.

Taylor, P. J. (2014). A Research Odyssey: from Interlocking Network Model to Extraordinary Cities. Tijdschrift Voor Economische En Sociale Geografie, 105(4), 387-397

Tobler W.R. (1975). Spatial interaction patterns. IIASA, 39 p. http://www.iiasa.ac.at

Torre, A., \& Rallet, A. (2005). Proximity and localization. Regional studies, 39(1), 47-59.

Torre, A., \& Wallet, F. (Eds.). (2014). Regional development and proximity relations. Edward Elgar Publishing.

Uzzi, B., \& Gillespie, J. J. (2002). Knowledge spillover in corporate financing networks: embeddedness and the firm's debt performance. Strategic Management Journal, 23(7), 595-618.

Van Looy D.B., Vereyen C., Schmoch U. (2014). Patent Statistics: Concordance IPC V8 - NACE REV.2, Eurostat.

Wasserman, S., \& Faust, K. (1994). Social network analysis: Methods and applications (Vol. 8). Cambridge university press.

White D.R. (2009). Innovation in the context of networks, hierarchies and cohesion, in Lane D., van der Leeuw S., Pumain D., West G., Complexity perspectives in innovation and social change, methodos series 7. 153-193

Yan, B., \& Luo, J. (2017). Measuring technological distance for patent mapping. Journal of the Association for Information Science and Technology, 68(2), 423-437. 